Published in final edited form as:

Anal Chem. 2010 June 15; 82(12): 4723-4741. doi:10.1021/ac101075n.

\title{
Electrochemical Sensors
}

\author{
Benjamin J. Privett, Jae Ho Shin, and Mark H. Schoenfisch \\ Department of Chemistry, University of North Carolina at Chapel Hill, Chapel Hill, and North \\ Carolina 27599. Department of Chemistry, Kwangwoon University, Seoul 139-701, Korea
}

This review covers scholarly articles published in 2008 and 2009 related to the field of electrochemical sensors. Emphasis was given to full papers reporting on fundamental advances in reference electrodes, potentiometric, voltammetric, and biosensors as well as reviews covering these fields.

Papers were selected by conducting keyword searches of SciFinder Scholar/CAS and ISI Web of Knowledge and by scouring the tables of contents of select analytical journals for relevant electrochemical sensor topics. Only reviews and original articles written in English were considered. Due to space, our review represents only a sample of the total body of literature. The selection of references was focused on those reporting new theory, sensing techniques, or materials, rather than applications of previously developed sensors. Furthermore, hybrid techniques or analytical methodologies employing electrochemical sensors for analyte detection (e.g., electrophoresis or chromatography) were also excluded to maintain focus on new sensor advances.

We remind our readers that the intention of this review is to provide a snapshot of electrochemical sensor development during 2008 - 2009. This review represents the author's subjective view of the most important advances in select journals. We recognize that some articles detailing important advances in the field may have been inadvertently left out. We apologize for these inevitable oversights and point readers to the numerous review articles that we have included for additional references.

\section{POTENTIOMETRIC SENSORS}

\section{Reviews}

Bobacka et al. published a broad overview on the electrochemical theory related to potentiometry response, including both classical equilibrium and advanced local-/nonequilibrium models (1). The review also covered recent advances in solid-contact and miniaturized ion-selective electrodes (ISEs) with a special emphasis on the use of conducting polymers as ion-to-electron transducers (324 citations).

Increasing interest in the use of potentiometric sensors for biological applications has generated demand for miniaturized ISEs. Bakker and Pretsch highlighted recent developments in nanoscale potentiometry, focusing on both understanding the interfacial films at the outer and inner side of the ion-selective membrane, and improving performance characteristics such as detection limits, biocompatibility, and sensor stability (77 citations) (2).

In the last three decades, the International Union of Pure and Applied Chemistry (IUPAC) has published several documents with the purpose of achieving standardized nomenclature and methodology in the field of potentiometric ISEs. Lindner and Umezawa updated the most recent IUPAC recommendations on how detection limits, selectivity coefficients, and calibration curves should be determined (3). The report also suggested measurement 
protocols for evaluating planar microfabricated electrodes with solid- or liquid-contact layers (103 citations).

Lindner and Gyurcsányi highlighted the importance of using conducting or redox polymers as solid-contact transducers for fabricating all-solid-state potentiometric sensors, and provided several criteria for evaluating solid-contact ISEs (120 citations) (4). Faridbod et al. reviewed studies utilizing conducting polymers for potentiometric sensing (5). Conducting polymer-based ISEs have been employed for the determination of more than 60 inorganic ions, and their electroanalytical properties depend on the types of conducting polymers used to construct the solid-contact layer (632 citations).

\section{Materials, lonophores, and lon Exchangers}

The introduction of new ion recognition chemistries has historically been a major focus of ISE research and remains so today. Kim, Nam, and co-workers detailed the synthesis of 7deoxycholic amide or cholane derivatives containing C3-bipyridyl and C12-dithiocarbamoyl groups, and C3-bithiophenyl with C12-dithiocarbamoyl groups as silver(I) ionophores (6).

The potentiometric sensors exhibited high selectivity $\left(\log K_{\mathrm{Ag}^{+}, \mathrm{M}^{7+}}^{P O T}<-5.5\right)$ towards silver $(\mathrm{Ag})$ (I) ions over other transition metal ions (i.e.., $\mathrm{M}^{\mathrm{Z+}}=\operatorname{zinc}(\mathrm{Zn})^{2+}$, lead $(\mathrm{Pb})^{2+}$, nickel $(\mathrm{Ni})^{2+}$, and cobalt $\left.(\mathrm{Co})^{2+}\right)$ with a Nernstian response slope of $59 \mathrm{mV} \cdot \mathrm{decade}^{-1}$ and detection limits of $10^{-7}$ to $10^{-6} \mathrm{M}$.

Mashhadizadeh and co-workers reported the use of Ag ion-selective membrane electrodes based on the podand of 1,1' -thia-bis-1[1-(chloroethan-2-acetamid-a-oxy)] naphtol as a neutral carrier (7). The authors evaluated the influence of the type and concentration of multiple membrane components such as plasticizers and lipophilic additives on the potentiometric performance. The electrode exhibited a Nernstian response slope of $59 \pm 1$ $\mathrm{mV} \cdot$ decade $^{-1}$ ranging from $100 \mathrm{nM}$ to $13 \mathrm{mM}$, a detection limit of $86 \mathrm{nM}$, and a rapid response time of $<10 \mathrm{~s}$.

The Bochenska group has demonstrated the utility of a series of lower rim substituted $p$-tertbutyl-calix[4]arene derivatives as cation-selective neutral carriers (8). Specifically, they employed tetra-substituted $p$-tert-butyl-calix[4]arene thioamides in a poly(vinyl chloride) (PVC) matrix as $\mathrm{Pb}(\mathrm{II})$-selective ionophores The optimized membrane composition consisting of PVC, calix[4]-thiomorpholide, and $o$-nitrophenyl octylether ( $o$-NPOE) exhibited high selectivities $\left(\log K_{\mathrm{Pb}^{2+} . \mathrm{M}}^{\mathrm{POT}}<-3\right.$ ) over copper $(\mathrm{Cu})^{2+}$, cadmium $(\mathrm{Cd})^{2+}$, manganese $(\mathrm{Mn})^{2+}, \mathrm{Zn}^{2+}, \mathrm{Ni}^{2+}$, and $\mathrm{Co}^{2+}$, and a Nernstian slope of $29.5 \mathrm{mV} \cdot \mathrm{decade}^{-1}$.

$\mathrm{Li}$ et al. reported the use of electrically conductive polyaminoanthraquinone (PAAQ) microparticles $\left(5.0 \times 10^{-5} \mathrm{~S} \cdot \mathrm{cm}^{-1}\right.$ at $15^{\circ} \mathrm{C}$; the particle size was not mentioned) as a new class of $\mathrm{Pb}$ (II) ionophores (9). The potentiometric response was modulated by both the loading content of PAAQ particles and thickness of the PVC polymeric membrane. The resulting optimized $\mathrm{Pb}$ (II) ISEs provided superior sensor performance over those based on traditional ionophores in terms of dynamic linear range $(2.5 \mu \mathrm{M}$ to $100 \mathrm{mM})$, detection limit $(776 \mathrm{nM})$, and response time $(<12 \mathrm{~s})$.

Gupta and co-workers described the use of 4-tert-butylthiacalix[4]arene as a neutral carrier to prepare Co(II) ISEs (10). The membrane, comprising of a calix[4]arene derivative, PVC, sodium tetraphenylborate (NaTPB), and (o-NPOE), exhibited a near-Nernstian slope of 30.0 $\mathrm{mV} \cdot \mathrm{decade}^{-1}$, a wide dynamic concentration range from $5.3 \mu \mathrm{M}$ to $100 \mathrm{mM}$, and a detection limit of $0.30 \mathrm{ppm}$. The utility of the sensor was demonstrated by determining Co(II) ion concentrations in waste water and beer samples. 
Ma et al. reported on the design of a new barium (Ba)(II) ion-selective ionophore derived from a macrocyclic tetrabasic ligand $\left(\mathrm{H}_{4} \mathrm{~L}\right)(11)$. The use of $\mathrm{H}_{4} \mathrm{~L}$-based neutral carriers provided a couple of distinct advantages, including facile and inexpensive synthetic procedures, and reduced toxicity toward biological systems compared to previously reported $\mathrm{Ba}$ (II) ionophores derived from crown ethers and calixarenes. The electrode exhibited a Nernstian slope of $29.7 \pm 0.2 \mathrm{mV} \cdot \mathrm{decade}^{-1}$, a wide linear range of $3.6 \mu \mathrm{M}$ to $100 \mathrm{mM}$, and a detection limit of $1.9 \mu \mathrm{M}$.

A new aluminum (Al)(III) ionophore, 6-(4-nitrophenyl)-2-phenyl-4-(thiophen-2-yl)-3,5diaza-bicyclo[3.1.0]hex-2-ene was synthesized by Arvand and Asadollahzadeh (12). The potentiometric membrane was composed of $30 \%$ poly(vinyl chloride), $3 \%$ ionophore, $62 \%$ acetophenone, and 5\% oleic acid. The resulting $\mathrm{Al}(\mathrm{III})$-selective sensors exhibited improved potentiometric performance compared to previously reported sensors with respect to Nernstian response $\left(19.6 \pm 0.4 \mathrm{mV} \cdot \mathrm{decade}^{-1}\right)$, detection limit $(63 \mu \mathrm{M})$, response time $(\sim 10$ s), and lifetime (up to 3 months). The Al(III) ISE was also successfully employed to determine $\mathrm{Al}(\mathrm{III})$ ion concentration in pharmaceutical (e.g., $\mathrm{Al}$ magnesium syrup), food (e.g., tea leaves), and environmental (e.g., tap and mineral water) samples.

The Meyerhoff group has made significant progress in the development of anion-selective membranes based on a series of metalloporphyrin complexes. Meyerhoff and Pietrzak reported on rhodium (Rh)(III) porphyrin and salophen derivatives as potential nitrite $\left(\mathrm{NO}_{2}{ }^{-}\right)$ ionophores (13). The $\mathrm{Rh}(\mathrm{III})$ porphyrin-based nitrite ISEs exhibited improved selectivities over lipophilic anions (e.g., salicylate, perchlorate, and thiocyanate), with deviation from the classical Hofmeister pattern. The resulting sensors were characterized by a Nernstian response slope $\left(\sim 59 \mathrm{mV} \cdot \mathrm{decade}^{-1}\right)$ towards $\mathrm{NO}_{2}{ }^{-}$and detection limits of $5 \mu \mathrm{M}$.

Kim and co-workers demonstrated the use of a functionalized conducting polymer film as a potentiometric sensing membrane for monohydrogen phosphate $\left(\mathrm{HPO}_{4}{ }^{2-}\right)(14)$. A bis(terthiophene)-appended uranyl-salophen (TUS) complex was electrochemically polymerized (i.e., poly-TUS) and deposited on a glassy carbon electrode. The resulting electrically conductive poly-TUS sensor exhibited excellent potentiometric properties with a linear response toward $\mathrm{HPO}_{4}{ }^{2-}$ from $32 \mu \mathrm{M}$ to $100 \mathrm{mM}$ (at $\mathrm{pH} 8.2$ ), a slope of -30 $\mathrm{mV} \cdot$ decade $^{-1}$, a detection limit of $10 \mu \mathrm{M}$, and a response time of $<10 \mathrm{~s}$.

Gupta et al. reported the fabrication of a potentiometric chloride $\left(\mathrm{Cl}^{-}\right)$sensor based on 2-(1H-imidazol [4,5-f] [1,10]-phenanthroline-2-yl)-6-methoxyphenol (HIPM), which forms a complex with chloride ions via hydrogen bonding interactions (15). The sensor membrane (poly(vinyl chloride): o-nitrophenyl octyl ether: HIPM: cetryltrimethylammonium bromide, 31:60:7:3 in w/w\%) exhibited excellent response properties, including enhanced selectivities towards chloride over common interfering anions $\left(\log K_{\mathrm{Cl}^{-}, \mathrm{B}}^{P O T}=-3.7,-2.9,-4.5\right.$, and -4.5 for $\mathrm{B}=\mathrm{SCN}^{-}, \mathrm{ClO}_{4}{ }^{-}, \mathrm{NO}_{3}{ }^{-}$, and $\mathrm{HPO}_{4}{ }^{2-}$ ), a Nernstian slope of $-59.8 \mathrm{mV} \cdot \mathrm{decade}^{-1}$ in the range of $50 \mathrm{nM}$ to $100 \mathrm{mM}$, and a low detection limit (10 nM). Babu and co-workers also reported on the synthesis of a calix[4]arene derivative based on a ureido moiety in 1,3alternate conformation as an ionophoric receptor for potentiometric chloride sensing (16). The electrode exhibited a near-Nernstian slope of $-55.7 \mathrm{mV} \cdot \mathrm{decade}^{-1}$ from $10 \mu \mathrm{M}$ to 100 $\mathrm{mM}$ with a detection limit of $25 \mu \mathrm{M}$.

Direct potentiometry and indirect potentiometric titrations for the determination of organic medicinal drugs (i.e., pharmacologically relevant ionic species) are important applications of ISEs. Katsu et al. described the potentiometric determination of caffeine $\left(\mathrm{pK}_{\mathrm{a}}=\sim 0.7\right)$ via conversion of caffeine to caffeinium ion (a protonated form of caffeine) at $\mathrm{pH} 2$ (17). The sensor membrane, consisting of tetrakis[3,5-bis(2-methoxyhexafluoro-2-

propyl)phenyl]borate and 2-fluoro-2' -nitrodiphenyl ether, exhibited a dielectric constant of 
$\varepsilon=50$, and showed markedly enhanced analyte response with respect to sensitivity (55 $\mathrm{mV} \cdot$ decade $\left.^{-1}\right)$, dynamic range $(10 \mu \mathrm{M}$ to $100 \mathrm{mM})$ and detection limit $(50 \mu \mathrm{M})$.

To detect ipratropium $\left(\mathrm{IP}^{+}\right)$, a synthetic quaternary ammonium antimuscarinic agent with peripheral effects in pharmaceutical samples, Hassouna and Elsuccary employed ipratropium-tetraphenylborate (IP-TPB) as an ion exchanger in a poly(vinyl chloride) membrane (18). The resulting sensor demonstrated excellent response to $\mathrm{IP}^{+}$with a sensitivity of $61.4 \mathrm{mV} \cdot$ decade $^{-1}$ over a range of $10 \mu \mathrm{M}$ to $10 \mathrm{mM}$ between $\mathrm{pH} 6.5$ and 9.0 , and a detection limit of $5.1 \mu \mathrm{M}$.

Zanjanchi et al. reported the use of organically modified sol-gel-derived materials to prepare strontium (Sr)(II) ion-selective membranes (19). The physical immobilization of the ionophore, 6-(4-nitrophenyl)-2-phenyl-4,4-dipropyl-3,5-diaza-bicyclo [3,1,0] hex-2-ene, into the sol-gel-based membrane resulted in a significant improvement in sensor lifetime ( $\sim 6$ months). Likewise, Zhou et al. employed a 2-acetylpyridine-functionalized nanoporous silica gel to fabricate chromium (Cr)(III) ion-selective carbon paste electrodes (20). A 2acetylpyridyl group modified on the nanoporous silica gel served as the ionophore for selectively binding with $\mathrm{Cr}(\mathrm{III})$. The resulting electrode exhibited excellent sensor performance, with a linear response toward $\mathrm{Cr}(\mathrm{III})$ ions in the range of $10 \mathrm{nM}$ to $1.0 \mathrm{mM}$, sensitivity of $19.8 \pm 0.2 \mathrm{mV} \cdot$ decade $^{-1}$ and a detection limit of $8.0 \mathrm{nM}$. However, the sensor response was rather slow $(\sim 55 \mathrm{~s})$.

Javanbakht et al. described the use of molecular imprinting to fabricate a potentiometric sensor for hydroxyzine, an antihistaminic and analgesic agent (21). The imprinted polymer membrane was prepared by polymerizing methacrylic acid and ethylene glycol dimethacrylate in the presence of hydroxyzine dihydrochloride as a template molecule. The hydroxyzine was then removed by washing with methanol/acetic acid $(10: 1, \mathrm{v} / \mathrm{v})$. The resulting sensor provided a good analytical response towards hydroxyzine with a Nernstian response of $29.4 \pm 1.0 \mathrm{mV} \cdot$ decade $^{-1}$ from $1.0 \mu \mathrm{M}$ to $10 \mathrm{mM}$, a detection limit of $700 \mathrm{nM}$, and a response time of $\sim 15 \mathrm{~s}$.

The combinational use of room temperature ionic liquids (RTILs) and multi-walled carbon nanotubes (MWCNTs) were described by Ganjali and coworkers in a strategy to improve the potentiometric properties of carbon paste ISEs (22). An erbium(III) ion-selective carbon paste was prepared using graphite powder, 5-(dimethylamino) naphthalene-1-sulfonyl 4phenylsemicarbazide as an ionophoric receptor, MWCNTs, and 1-n-butyl-3methylimidazolium tetrafluoroborate as an ionic liquid binder with high electrical conductivity. The resulting electrode modified with RTILs and MWCNTs exhibited enhanced sensitivity $\left(19.8 \pm 0.3 \mathrm{mV} \cdot \mathrm{decade}^{-1}\right)$, response time $(16 \mathrm{~s})$, and lifetime $(\sim 3$ months), compared to control (i.e., unmodified) carbon paste electrodes.

Evtugyn et al. evaluated the sensitivity and selectivity of several $\mathrm{Ag}(\mathrm{I})$-ion selective carbon electrodes modified with polyaniline and thiacalix[4]arenes containing amidopyridine, morpholide, pyrrolidine, or hydrazide (23). The potentiometric properties of the electrodes depended on the steric accessibility and flexibility of the macrocyclic binding site in the receptor structures. The limit of the detection of the resulting sensors was reported to be $35-$ $100 \mathrm{nM}$.

\section{Detection Limits and Selectivity}

Since the first report on the use of high fluorinated liquid phases as a new class of sensing materials for ISEs in 2005, Bühlmann and co-workers continued to design various ionselective sensors with such membranes. Specifically, Boswell et al. described the synthesis and characterization of fluorophilic $\mathrm{H}^{+}$ionophores that are compatible with nonpolar and 
nonpolarizable fluorinated phases (24). The $\mathrm{pH}$ sensor based on the fluorous membrane

exhibited exceptionally high selectivity over potassium ions $\left(\log K_{\mathrm{H}^{+}, \mathrm{K}^{+}}^{P O T}<-12.8\right)$ with a wide dynamic range from $\mathrm{pH} 5$ to 13. In a similar strategy, Lai et al. demonstrated fluorous $\mathrm{pH}$ electrodes consisting of fluorinated membranes prepared using poly[4,5-difluoro-2,2bis(trifluoromethyl)-1,3-dioxole]-co-poly(tetrafluoroethylene) (Teflon AF2400) as a polymer matrix, a linear perfluorooligoether as a plasticizer, sodium tetrakis[3,5bis(perfluorohexyl) phenyl]borate providing ionic sites, and bis[(perfluorooctyl)propyl]-2,2,2-trifluoroethylamine as an $\mathrm{H}^{+}$ionophore (25). The blending effects of Teflon AF2400 with the linear perfluorooligoether plasticizer on the electrical resistance, response slope, selectivities, and long-term stability were reported. Furthermore, the authors noted that $\mathrm{C}(=\mathrm{O}) \mathrm{F}$ groups present in Teflon AF2400 allow for further functional modifications of the polymer.

Potentiometric measurements of ionic activity in the presence of high concentrations of background electrolytes remain challenging. The Bakker group continued to develop unique strategies for lowering the detection limit of polymer ion-selective membrane electrodes.

Wang, Bakker, and co-workers demonstrated the detection of $\mathrm{Cd}(\mathrm{II})$ ion at trace levels down to $1 \mathrm{ppb}$ in $0.5 \mathrm{M} \mathrm{NaCl}$, mimicking seawater (26). The overall measurement apparatus consisted of online electrochemically-modulated preconcentration and matrix elimination cell, and the potentiometric detection cell equipped with solid-contact Cd(II) ISEs.

\section{New Concepts, Mechanisms, and Characterization}

The Meyerhoff group reported the use of potentiometric heparin sensors to detect oversulfated chondroitin sulfate (OSCS), a serious contaminant in heparin preparations (27). The presence of a high density of polyanion OSCS in heparin samples causes significant differences in the potentiometric response when compared to the response obtained with pure heparin. The method enabled the detection of very low concentrations (down to $0.5 \mathrm{wt}$ $\%$ ) of OSCS impurities in heparin samples.

Pietrzak and Meyerhoff demonstrated a simple method to measure the intracellular potassium concentration in red blood cells via the use of miniaturized potassium and sodium ISEs (28). The unique advantage of this new approach includes no requirement for measurement of blood volumes due to the absence of a blood dilution step.

To improve biocompatibility of previous ammonium ISEs, Radomska and co-workers employed carboxylated poly(vinyl chloride) (PVC) matrixes doped with poly(ethylene glycol) (PEG) (29). The resulting electrode was able to monitor ammonium concentrations (ranging from 0.5 to $5 \mathrm{mM}$ ) continuously in a perfused cell reactor, while the signal remained stable for 7 days without significant biofouling formation.

Asif et al. reported on a potentiometric solid-state $\mathrm{Ca}^{2+}$ sensor fabricated by applying a calcium-selective PVC membrane on a silver-coated glass capillary electrode $(0.7 \mu \mathrm{m}$ in tip diameter) functionalized with zinc oxide nanorods $(100-120 \mathrm{~nm}$ in diameter and $0.9-1.0$ $\mu \mathrm{m}$ in length) (30). The sensor exhibited sufficient sensitivity and stability from $100 \mathrm{nM}$ to $10 \mathrm{mM}$ for intracellular measurements of calcium.

A composite polymer based on polyacrylate chemically grafted with a conducting polymer, poly(3,4-ethylenedioxythiophene), was employed by the Michalska group as a strategy for improving the potentiometric performance of all-solid-state potassium ISEs (31). The resulting membrane exhibited reduced electrical resistance compared to the ungrafted polyacrylate membrane, stable potentiometric responses, and lowered detection limits. Nagy and co-workers demonstrated the utility of a solid-contact potassium-selective electrode based on poly(3,4-ethylenedioxythiophene) electrochemically deposited on a micropipette 
(32). The potassium micropipette electrode was used for scanning electrochemical microscopy (SECM) imaging and in vivo potassium measurements in both plant and animal tissues.

The new concept of temperature pulse potentiometry was introduced by ChumbimuniTorres and coworkers using an all-solid-state $\mathrm{Cu}(\mathrm{II})$ sensor integrating a heating circuit under the electrode substrate (33). The local heating process (20 s heat pulse to a maximum of $60^{\circ} \mathrm{C}$ ) during potentiometric measurements provided several attractive benefits, including an increase in the sensor response ( 31 to $43 \mathrm{mV} \cdot \mathrm{decade}^{-1}$ ) and improved detection limits (down to $\sim 300 \mathrm{pM}$ calcium), while remaining stable (a potential drift of $0.2 \mathrm{mV} \cdot \mathrm{h}^{-1}$ ).

Michalska et al. introduced a strategy for improving the potentiometric performance of polymeric cation-selective electrodes via the combination of two different anionic sites (i.e., primary and interfering ions with the same counter anion) (34). Photopolymerized poly ( $n$ butyl acrylate) membrane-based potassium and calcium-selective electrodes were prepared as model systems by using potassium and sodium tetrakis[3,5-

bis(trifluoromethyl)phenyl]borate, and calcium and sodium tetrakis[3,5-

bis(trifluoromethyl)phenyl]borate, respectively. The electrodes containing two lipophilic salts exhibited lower detection limits and shorter sensor preconditioning times with superNernstian slopes towards primary ions when compared to the electrodes prepared with only primary cations.

The existence of water between the ion-selective membrane and the inner solid contact often leads to less than optimal sensor performance. To eliminate such undesirable water layers, Veder et al. demonstrated the use of a water-repellent copolymer, poly(methylmethacrylate)/ poly(decyl methacrylate), to fabricate ion-selective membrane electrodes (35). The solidcontact film of hydrophobic poly(3-octylthiophene 2,5-diyl) was used as the ion-to-electron transducer. The authors employed several techniques to evaluate the effect of the water layer on potentiometric performance, including electrochemical impedance spectroscopy (EIS), in situ neutron reflectometry/EIS, secondary mass spectrometry, and small-angle neutron scattering. Radu and co-workers also described the fabrication of solid-state lead(II) ionselective membrane electrodes using a solid contact of poly(3-octylthiophene), a solventprocessable conducting polymer (36). The conducting layer was simply deposited on a gold electrode via drop-casting.

The utility of nanomaterials (e.g., carbon nanotubes and fullerenes) has been extensively investigated, in a recent trend for designing solid contacts for potentiometric all-solid-state sensors. The Rius group published a series of papers related to solid contacts prepared from carbon nanotubes (37-40). The authors first described all-solid-state potassium ion-selective membrane electrodes based on a highly conductive solid-contact network built by spraying an aqueous suspension of single-walled carbon nanotubes (SWCNTs) (40) on an electrode surface. The resulting potassium electrode was highly stable and exhibited reproducible sensor performance with a slope of $58.4 \mathrm{mV} \cdot \mathrm{decade}^{-1}$, a detection limit of $3.2 \mu \mathrm{M}$, and a response time of $<10 \mathrm{~s}$. In a subsequent study, Crespo et al. focused on elucidating the transition mechanism involved when using carbon nanotubes as a three-dimensional ion-toelectron transduction network (37). Cyclic voltammetry and EIS studies revealed that the small resistance and a large bulk capacitance of the SWCNT-based electrodes led to the formation of nonfaradaic double layer charging of the porous SWCNTs. A similar approach was employed to develop a perchlorate-selective membrane electrode by using a multiwalled carbon nanotube (MWCNT)-derived solid contact (39). The electrode showed small signal drift of $0.22 \mathrm{mV} \cdot \mathrm{h}^{-1}$, a Nernstian slope of $57 \pm 3 \mathrm{mV} \cdot \mathrm{decade}^{-1}$, and a detection limit of $34 \mathrm{nM}$. 


\section{REFERENCE ELECTRODES}

Although more research effort has focused on the design and characterization of working electrodes (i.e., ISE), the reference electrode remains an equally vital part of electrochemical sensors. Recently, the development of solid-state reference electrodes has generated enormous interest due to their facilitation of sensor miniaturization. Guth et al. reviewed the recent advances in solid-state reference electrodes with specific attention to their availability, application, and suggestions to solve the problems associated with miniaturization (41).

Kisiel et al. described the fabrication of all-solid-state reference electrodes based on a poly(n-butyl acrylate) membrane via photopolymerization (42). A conducting polymer (i.e., polypyrrole) film was employed as an ion-to-electron transducing layer between a poly $(n-$ butyl acrylate) membrane and a glassy carbon electrode. The planar reference electrode response was insensitive to typical ionic species including $\mathrm{Na}^{+}, \mathrm{K}^{+}, \mathrm{Cl}^{-}$, and $\mathrm{NO}_{3}{ }^{-}$up to concentrations of $100 \mathrm{mM}$ over a $\mathrm{pH}$ range of 2 to 12 . Chen and Chou developed an allsolid-state reference electrode by electrodepositing a polypyrrole layer on an indium-tin oxide (ITO) surface, followed by the deposition of a Nafion film with no inner electrolyte (43). The reference electrode demonstrated stable potentials in solutions up to $2 \mathrm{M} \mathrm{KCl}$ and over a $\mathrm{pH}$ range of 2 to 12 for at least 4 months.

\section{VOLTAMMETRIC SENSORS}

\section{Reviews}

In 2008, the $50^{\text {th }}$ anniversary of the development of carbon paste electrodes (CPEs) was celebrated with the publication of a number of reviews detailing their history and recent advances. The chemical flexibility of CPEs has resulted in their ubiquity throughout the field of electrochemistry. In a fitting tribute to the field and to the inventor, Ralph Adams, Švancara and collegues recanted a collection of facts, figures, and curiosities related to CPEs from more than 2000 papers published from 1958 - 2008 (324 citations) (44). Advances related to CPEs continue, especially in their application for the detection of organic molecules. In a review covering the body of literature from $2004-2008$, Zima and coworkers detailed the use of CPEs that utilize nontraditional carbon materials (i.e., nanotubes and nanoparticles) and various chemical and biological modifications for the detection of organic molecules (i.e., pharmaceuticals and environmental pollutants) (223 citations) (45).

Metal amalgam electrodes (i.e., solid, paste, and composite) have been studied extensively as suitable replacements for potentially toxic mercury electrodes. Yospchuk and Barek reviewed an extensive array of amalgam working and reference electrodes reported from $2000-2008$, detailing their fabrication, operating parameters, and applications (92 citations) (46). Figures of merit such as operating potentials for each electrode type in a range of supporting electrolytes were included.

Stetter and Li published a tutorial review covering the field of amperometric gas sensors (116 citations) (47). The review covered general theory and reactions, construction, materials, and applications of a range of gas sensors. Special attention was given to improvements made through the incorporation of sensor arrays and nanotechnology into gas sensor platforms. Yogeswaran and Chen reviewed the use of nanowires as materials for electrochemical sensing (77 citations) (48). The authors discussed various nanowire synthetic strategies employed for the fabrication of electrochemical sensors and detailed a number of examples of nanowire-based sensors for a broad range of applications. 
The development of voltammetric sensors for environmental monitoring continues to be a focus of electrochemical research. Sensors capable of detecting trace quantities of heavy metals have been the subject of intense research for decades due to the toxicity and abundance of these contaminants in drinking water. Mays and Hussam reviewed the recent advances in the field of voltammetric arsenic sensors since 2001 (58 citations) (49). The authors described the principles of stripping voltammetry and reviewed various materials and techniques employed, as well as the figures of merit, for a range of electrochemical arsenic sensors. Bobrowski and coworkers surveyed techniques for both the detection and speciation of chromium ( $\mathrm{Cr}$ ) in the environment (173 citations) (50). After describing the principles of catalytic adsorptive stripping voltammetry, a number of methods for trace analysis were presented. Additionally, the authors highlighted commonly utilized strategies for the discrimination of $\mathrm{Cr}(\mathrm{IV})$, a highly toxic manufacturing byproduct, from $\mathrm{Cr}(\mathrm{III})$, an important nutrient.

\section{Theory, modeling, and analysis}

The widespread use of microelectrodes for electrochemical analysis has necessitated continued examination of the theory governing their operation. Microelectrodes are of particular interest due to the absence of ohmic drop during their use. However, Amatore and coworkers showed that in highly resistive solutions, resistance and current density is not uniform over the entire surface of the working electrode (51). The authors, utilizing quasiconformal mapping, demonstrated that the non-uniform ohmic drop observed in such solutions would significantly affect the resulting voltammograms. Using a similar numerical technique, the same group examined the diffusion processes at arrays of recessed microdisk electrodes (where electrode surfaces are not coplanar with the surrounding insulation) (52). The resulting theoretical treatment allowed the examination of the dependence of analyte diffusion on the geometry of the recessed microdisk electrodes. Using both simulations and experimental evidence, Gou and Lindner, explored the effect of electrode recess depth on the minimum distance between electrodes in an array required to obtain hemispherical diffusion (53). As a result, the shape of the cyclic voltammograms could be predicted at various electrode array geometries and in a variety of experimental conditions.

A number of reports focused on the electrochemical effects of electrode surface characteristics such as roughness and porosity. Amatore and coworkers examined the influence of electrode roughness on the capacitance and non-ideality of a self-assembled monolayer (SAM) using impedance spectroscopy and modeling (using a Helmholtz or Randles equivalent circuit) (54). The authors determined that microscopic (up to tens of $\mathrm{nm}$ ) roughness affected the non-ideality of the film, while macroscopic (hundereds of $\mathrm{nm}$ ) roughness affected the capacitance. Menshykau and Compton devised a model for predicting the deviation of cyclic voltammograms for porous electrodes from ideal (perfectly smooth) electrodes (55). When roughness was modeled as a set of cylindrical pores, an increase in cylindrical depth resulted in decreasing peak separation and current density.

Bae and colleagues reported a numerical model for a real conductometric molecular wire sensor (MWS), where binding of an analyte molecule only reduces the resulting signal rather than completely eliminating the signal (as is the case with an ideal MWS) (56). The authors found that the Stern-Volmer curve for real MWS's had a negative curvature, whereas ideal MWS's exhibited a positive curvature, matching previously reported experimental data. The conditions at which the analytical performance characteristics of a real MWS exceeds that of an ideal monoreceptor sensor was discussed.

Lee and Bond developed a method for electrochemically estimating the fraction of edge plane defects on highly ordered pyrolytic graphite (HOPG) electrodes (57). The authors utilized large-amplitude Fourier transformed ac voltammetry in combination with a surface 
active ferri/ferrocyanide redox probe to analyze HOPG electrodes with varying degrees of edge plane defects. Estimation of edge plane defect levels were made by examining the capacitance and faradaic ac and dc components of the resulting current.

Sheth and coworkers reported a concept for estimating the bulk concentration of analytes in small inhomogenous samples that cannot be stirred (58). The authors proposed a spatially averaging electrode that utilizes a 2D spiral shape capable of determining the $3 \mathrm{D}$ bulk concentrations. When tested experimentally, the unique shape of the electrode resulted in identical voltammetric current in both stirred and unstirred solutions, while traditional (e.g., cylindrical and disk-shaped) electrodes exhibit differing responses in stirred vs. unstirred solutions.

Ogurtsov and colleagues compared the effects of non-constant vs. constant-rate linear potential sweeps on the resulting voltammetric currents (59). Utilizing a model electrochemical system (potassium ferrocyanide at a glassy carbon electrode), the authors determined that signal and peak shape enhancements could be realized by altering the linearity of the potential sweeps via nonlinear staircase voltammetry.

\section{Materials}

Interest in micro- and nanoporous materials as electrochemical sensing platforms has continued to grow. Zhou and coworkers reported on the fabrication of a mesoporous sensor composed of carbon-fullerene materials (60). The resulting porous structure exhibited a high surface area and increased electron transfer kinetics for a variety of organic and inorganic species. The electrode greatly reduced the overvoltage of NADH oxidation, making it suitable for a variety of biosensing applications. Trammel and colleagues utilized template directed molecular imprinting to synthesize organosilicas with highly ordered nanostructures for detecting trinitrotoluene (TNT) (61). Templated diethylbenzene facilitated the preconcentration of TNT, which was then detected by square-wave voltammetry. The limit of detection of the ensuing TNT sensor was $5 \mathrm{ppb}$.

Park and coworkers reported a method for detecting glycated hemoglobin, a biomarker used to examine long-term blood glucose levels (62). The sensor was composed of a selfassembled monolayer (SAM) of thiophene-3-boronic acid synthesized on gold electrodes. When exposed to glycated hemoglobin, a reaction with boronic acid portion of the SAM resulted in its immobilization on the electrode. The surface-bound glycated hemoglobin was then detected via electrochemical impedance spectroscopy.

Safavi and coworkers fabricated a nanoscale copper hydroxide carbon ionic liquid electrode capable of simultaneously detecting glutathione (GSH) and glutathione disulfide (63). The complex formed between $\mathrm{Cu}$ (II) in the nanostructure and the thiol on GSH lowered the overpotential for oxidation. The resulting electrode exhibited detection limits of 30 and 15 $\mathrm{nM}$ for glutathione and glutathione disulfide, respectively without interference from cysteine, homocysteine, ascorbic acid, or uric acid.

Batista and coworkers utilized iron tetrapyridinoporphyrazine as a catalyst for the detection of estradiol valerate (EV) at a carbon paste electrode (64). The electrode exhibited a dynamic linear range of $45-450 \mu \mathrm{M}$ and a detection limit of $13 \mu \mathrm{M}$. The authors successfully applied the electrode for detection of EV in commercial preparations.

Gholicand and Amiri fabricated a nuclear fast red (NFR)/porous polypyrrole sensor capable of detecting methyldopa (MDA) and ascorbic acid (65). A polypyrrole film was electrosynthesized in the presence of NFR on a gold electrode and overoxidized to increase porosity of the sensor. The anionic NFR dopant increased selectivity over interferences such 
as oxalate, urea, and citrate. The resulting sensors exhibited limits of detection for MDA and ascorbic acid of $50 \mathrm{nM}$ and $5.8 \mu \mathrm{M}$, respectively.

Prasad and colleagues demonstrated the use of Shewanella bacteria as an electron transfer material for electrochemical sensors (66). The authors first examined the electrochemical characteristics of the bacteria adsorbed onto a screen-printed carbon electrode via cyclic voltammetry. The electroanalytical utility of this unique class of electroactive materials was demonstrated by utilizing the resulting sensor in detecting arsenite, hydrogen peroxide, and nitrite.

\section{Nanomaterials}

Carbon nanotubes (CNTs) are ideal materials for incorporation into electrochemical sensors due to their high surface area, high aspect ratio, and enhanced catalytic properties. Accordingly, researchers have continued to develop novel uses for these nanomaterials in electrochemical sensors at a rapid pace. Popp and coworkers developed a method for synthesizing an array of highly aligned self-supporting CNTs (67). The material was fabricated by growing the CNTs via chemical vapor deposition-chemical infiltration onto porous aluminum oxide substrates. Electrical contacts were made to each side of the material by etching the surface and sputtering with gold, resulting in a sandwich of aligned CNTs capped by gold contacts. The analytical utility of this CNT-based material was demonstrated by measuring the resistance changes across the CNT layer as a function of exposure to various gases (e.g., $\mathrm{O}_{2}, \mathrm{CO}$, and $\mathrm{H}_{2}$ ).

Dumitrescu and coworkers used lithography to fabricate ultramicroelectrodes composed of networks of single-walled CNTs (68). After growing the nanotubes on silicon dioxide surfaces, gold contacts were applied via evaporative deposition, photoresist insulation was deposited, and the $100 \mu \mathrm{M}$ electrode was formed by photolithographic removal of a disk of insulation, revealing the bare nanotubes. The authors noted that the resulting electrodes were well suited for a variety of studies due to their low background current and decreased double-layer charging in comparison to macroelectrodes. Additionally, their low surface area and capacitance resulted in fast response times in comparison to metal ultramicroelectrodes.

Khan and coworkers utilized multi-walled carbon nanotubes (MWCNTs) for the fabrication of sensors capable of detection chemical warfare agent (CWA) mimics (69). Ferroceneamino acid conjugates capable of interacting with a variety of CWA mimics were immobilized to MWCNTs adhered to indium tin oxide surfaces. Using alternating current voltammetry and capacitance measurements, the CWA mimics were quantified in aqueous solution, with resulting detection limits from $10 \mathrm{pM}-10 \mathrm{nM}$ depending on the analyte.

Kachoosangi and coworkers devised a sensing scheme for amine-containing compounds where their presence was measured at either a capsaicin-modified MWCNT electrode or a pchloranil-modified CPE (70). An electrochemically-initiated reaction formed an adduct between the amine and capsaicin or p-chloranil. As a result, the voltammetric response due to capsaicin and p-chloranil was reduced. The analyte concentration was then determined by measuring the magnitude of the signal reduction. The limits of detection for representative amines, benzocaine and lidocaine, were 4.2 and $7.3 \mu \mathrm{M}$, respectively.

Rahman and colleagues synthesized nanofibers from poly(1,5-diaminonapthalene) for use as a water sensor for non-aqueous solvents (71). The nanofibers were suspended between two closely-spaced gold electrodes, forming the water sensor. Upon addition of various percentages of water in acetonitrile, detection was performed using double-step 
chronoamperometry. The resulting sensor could detect up to $20 \%$ (v:v) water in acetonitrile with a detection limit of $0.01 \%$.

Wei and coworkers developed a method for fabricating boron-doped diamond (BDD) nanograss sensors, which combined the advantages of BDD (i.e., stability, wide potential window, and low background current) with the fast electron transfer and enhanced catalytic activity afforded by the nanostructure (72). The nanograss was formed by reactive ion etching, where the boron atoms act as a mask, forming nanograss with diameters ranging from 5-20 nm. The authors compared the response of the resulting sensor to a sensor composed of a pure BDD film, and reported that sensitivity and selectivity for both dopamine and uric acid were enhanced at the nanostructured electrode. Likewise, Hutton and coworkers modified polycrystalline BDD disk electrodes with platinum $(\mathrm{Pt})$ nanoparticles to fabricate a dissolved oxygen sensor (73). The Pt nanoparticles were synthesized by electrodeposition on the electrode, resulting in a bimodal distribution of 1 and $3 \mathrm{~nm}$ sizes. The Pt nanoparticle-modified BDD electrodes exhibited very low background currents (due to the BDD) compared to Pt electrodes and could detect oxygen at levels as low as $1 \mathrm{ppb}$.

Karam and Halaoui reported on the fabrication of Pt nanoparticle arrays assembled in low densities in polyelectrolyte for the detection of hydrogen peroxide (74). The authors controlled the surface coverage of nanoparticles by varying the exposure time of the electrode to the nanoparticles in solution. Although the response to hydrogen peroxide was reduced with decreasing nanoparticle coverage, signal stability at a constant anodic potential was increased at the lower Pt nanoparticle densities. In fact, sensors coated with a low density of Pt nanoparticles behaved in a similar manner those composed of low density arrays of ultramicroelectrodes. This finding is especially useful for applications where continuous $\mathrm{H}_{2} \mathrm{O}_{2}$ sensing is required, as it simplifies construction, reduces the amount of $\mathrm{Pt}$ needed, and thus lowers the cost of sensor fabrication.

Crowley and coworkers utilized polyanaline nanoparticles doped with dodecylbenzene sulfonate to detect ammonia in aqueous soltions (75). Particles were deposited via inkjet printing onto screen printed carbon electrodes, resulting in an environmentally benign, lowcost method for sensor assembly. The sensor was characterized via amperometry and exhibited a detection limit for ammonia of $20 \mu \mathrm{M}$.

Wen and colleagues synthesized amorphous iron/nickel/platinum nanoparticles and applied them to a glassy carbon electrode for the detection of thiols (76). The length of the nanoparticles was tuned by varying heating during phase-transfer synthesis. The resulting sensors exhibited enhanced electrocatalytic activity towards cysteine oxidation due to both the alloy material and nanoparticle size, with a limit of detection for cysteine of $50 \mathrm{nM}$.

\section{Microelectrodes}

Arrays of microelectrodes continue to be an area of intense research in the field of electrochemical sensors. Zhang and coworkers developed a microdisk array of individually addressable carbon fiber electrodes and demonstrated their use in high spatial and temporal resolution detection of neurotransmitter release (77). The arrays were fabricated by pulling the tip of a multibarrel glass capillary containing a carbon fiber $(2.5 \mu \mathrm{m}$ diameter) in each capillary, followed by polishing to form a planar carbon microdisk surface. The resulting sensors were utilized to examine sub-cellular heterogeneity in exocytosis from single cells, with resolution as low as $5 \mu \mathrm{m}$.

Zachek and coworkers fabricated microarray electrodes $(50 \times 10 \mu \mathrm{m})$ composed of pyrolyzed carbon via photolithography and exposure to high temperatures $\left(1000{ }^{\circ} \mathrm{C}\right)(78)$. 
The resulting electrodes were characterized by fast scan cyclic voltammetry and found to be electrochemically similar to carbon fiber microelectrodes commonly used for quantifying neurotransmitter release. Unlike carbon fiber electrodes, the pyrolyzed carbon microarrays can be batch fabricated via photolithography, allowing for precise control of dimensions and excellent sensor-to-sensor reproducibility. The authors demonstrated the use of the microarray sensors by simultaneously detecting dopamine and oxygen without the observation of crosstalk between the sensors.

The continuous improvement of microfabrication techniques has enabled researchers to fabricate ultramicroelectrodes of increasingly diminutive size. Li and coworkers demonstrated the fabrication of Pt disk ultramicroelectrodes of exceedingly small diameter $(1-3 \mathrm{~nm})(79)$. A Pt microwire was placed in a bilayer quartz capillary and then pulled and polished to result in the microdisk electrodes, which were characterized by transmission electron microscopy and steady-state voltammetry. The electrodes were used to measure the electron transfer rate constants for a variety of redox molecules. The authors noted that these electrodes would be suitable for measurements of ultrafast electron transfer kinetics or single molecule applications.

Yang and Sun utilized a similar method to fabricate dual submicron $(\sim 200 \mathrm{~nm})$ diameter Pt disk electrodes (80). Thin platinum wires were placed inside a dual barrel capillary, pulled to form a sharp point, and polished to form two small platinum disk electrodes. The sensors could be controlled independently or used in generation-collection mode, and exhibited low charging currents due to their small size. Hu and colleagues utilized focused ion beam milling to fabricate BDD microelectrodes of a few microns diameter (81). Electrophoretic paint was applied to insulate the substrate and a focused ion beam was employed at a sideon geometry to sputter away insulation, forming the active BDD electrode area. The electrodes exhibited low background currents in comparison to similarly-sized platinum and carbon fiber electrodes.

Strand and Venton compared the sensitivity of small $(1-3 \mu \mathrm{m})$ carbon fiber electrodes prepared via flame and electrochemical etching (82). The authors noted that flame etching increased kinetics and $\mathrm{S} / \mathrm{N}$, resulting in better electrochemical performance than normal or electrochemically etched carbon fibers. Furthermore, overoxidation of the flame-etched electrodes further improved sensitivity. Nanostructures resulting from the flame etching process were surmised to be the source of the improvement in sensitivity.

Pai and coworkers fabricated high surface area 3D gold microelectrodes suitable for incorporation into lab-on-a-chip devices (83). The patterned structure of the gold microelectrodes was formed by applying a patterned silicon mold, heat, and pressure to the gold electrodes, resulting in square pillars with $20 \mu \mathrm{m}$ sides and a depth of $18 \mu \mathrm{m}$. The electrodes exhibited improved limits of detection for catechol, and good stability over 8 months of use. The authors noted that the patterning process utilized in this method would be amenable to fabricating other pattern geometries.

Jena and Raj fabricated arrays of gold nanoelectrodes for simultaneously detecting arsenic, mercury, and copper (84). The electrode arrays were formed via the self-assembly of gold nanoparticles ( $5-6 \mathrm{~nm}$ dia) onto a silicate network to yield a SAM-modified gold electrode. The resulting electrodes exhibited detection limits of $20 \mathrm{ppt}$ for arsenic and mercury when detected via square wave anodic stripping voltammetry, with no interference from the copper peak. 


\section{Stripping Voltammetry}

The high surface area of nanomaterials, and in particular nanotubes, makes them ideal for use in stripping voltammetry. Janegitz and coworkers reported an electrode capable of the sensitive quantification of $\mathrm{Cu}(\mathrm{II})$ (85). The electrode was composed of carbon nanotube paste modified with crosslinked chitosan, a hydroxyl- and amine-rich polysaccharide capable of chelating heavy metals. The sensor exhibited a limit of detection of $10 \mathrm{nM}$ in oxygenated conditions after an accumulation period of $300 \mathrm{~s}$. Morton and coworkers utilized a similar strategy for detecting trace quantities of $\mathrm{Cu}$ (II) and $\mathrm{Pb}$ (II) in water (86). Cysteinemodofied multi-walled carbon nanotubes (MWCNTs) were cast onto glassy carbon electrodes. After an accumulation period of $10 \mathrm{~min}$, the limits of detection of the optimized sensors were reported as 1 and $15 \mathrm{ppb}$ for $\mathrm{Pb}(\mathrm{II})$ and $\mathrm{Cu}(\mathrm{II})$, respectively.

$\mathrm{Xu}$ and colleagues modified a glassy carbon electrode with a Nafion film containing MWCNTs and bismuth (Bi), resulting in electrodes capable of detecting $\mathrm{Pb}$ (II) and $\mathrm{Cd}$ (II) (87). With this combination, the authors took advantage of the wide potential window and insensitivity of $\mathrm{Bi}$ to $\mathrm{O}_{2}$, as well as the high surface area and strong adsorptive capabilities of the MWCNTs. The sensors exhibited limits of detections for $\mathrm{Pb}(\mathrm{II})$ and $\mathrm{Cd}(\mathrm{II})$ of 25 and $40 \mathrm{ppt}$, respectively.

Kachoosangi and coworkers modified a basal plane pyrolytic graphite electrode with MWCNTs, thus enabling the quantitation of capsaicin using adsorptive stripping voltammetry (70). The sensor performance allowed for a capsaicin detection limit of 0.31 $\mu \mathrm{M}$ and dynamic linear range from $0.5-60 \mu \mathrm{M}$. The authors also demonstrated a carbonnanotube-modified screen printed electrode with a limit of detection of $0.45 \mu \mathrm{M}$.

A large body of research has focused on the use of nanoparticles in sensors for stripping voltammetry. Toghill and coworkers utilized antimony ( $\mathrm{Sb}$ ) nanoparticle-modified borondoped diamond (BDD) electrodes to simultaneously detect $\mathrm{Cd}$ (II) and $\mathrm{Pb}$ (II) (88). The enhancement provided by the $\mathrm{Sb}$ particles resulted in two discernable stripping peaks corresponding to $\mathrm{Cd}$ (II) and $\mathrm{Pb}$ (II), whereas $\mathrm{Pb}$ (II) interfered with $\mathrm{Cd}$ (II) detection at unmodified BDD electrodes.

Yantasee and coworkers reported a method for detecting $\mathrm{Pb}$ in challenging matrices such as urine (89). Magnetic iron oxide nanoparticles modified with dimercaptosuccinic acid, a molecule with a high affinity for heavy metals, were dispersed in the sample matrix where they chelated $\mathrm{Pb}$. The particles were subsequently concentrated at a glassy carbon of CPE affixed to a magnetic electrode. Stripping voltammetry was then performed to determine the concentration of $\mathrm{Pb}$. The resulting sensors exhibited a dynamic linear range of $0-50 \mathrm{ppb}$ and a limit of detection of $0.5 \mathrm{ppb}$. The authors demonstrated sensor utility by simultaneously detecting $\mathrm{Cd}, \mathrm{Pb}, \mathrm{Cu}$, and $\mathrm{Ag}$ in water samples at concentrations below 1 ppb.

Rico and colleagues modified screen-printed carbon electrodes with bismuth (Bi) nanoparticles for the detection of trace zinc ( $\mathrm{Zn}$ ) (II), $\mathrm{Cd}(\mathrm{II})$ and $\mathrm{Pb}(\mathrm{II})$ (90). A Bi solution was cast on the electrode, resulting in particle formation after solvent evaporation. The resulting limits of detection ranged from $0.9-4.9 \mathrm{ppb}$ after a 120 deposition period. Tesarova and coworkers fabricated an antimony ( $\mathrm{Sb}$ ) film carbon paste electrode capable of detecting trace heavy metals (91). The Sb film electrode compared favorably to $\mathrm{Bi}$ and mercury $(\mathrm{Hg})$ film electrodes, with better performance in acidic conditions, narrower stripping signals for $\mathrm{Cd}(\mathrm{II})$ and $\mathrm{Pb}(\mathrm{II})$, and improved overall response to $\mathrm{Cd}(\mathrm{II})$.

Zou and coworkers utilized a glassy carbon electrode modified with a Langmuir-Blodgett film of 25,27-Dimethoxy-26-(N-trichloroacetyl)carbamoyloxy-p-tert-butylcalix[4]arene 
(DCA) to simultaneously quantify thallium (Tl)(I) and $\mathrm{Pb}(\mathrm{II})$, two highly toxic industrial pollutants (92). The ring structure of DCA provided reduction site for $\mathrm{Tl}(\mathrm{I})$ and $\mathrm{Pb}(\mathrm{II})$ instead of forming a complex with the metals. The resulting sensor exhibited limits of detection of 20 and $80 \mathrm{nM}$ for $\mathrm{Tl}(\mathrm{I})$ and $\mathrm{Pb}(\mathrm{II})$, respectively.

Delgado and coworkers described the fabrication of a nickel hexacyanoferrate-aluminum oxide-modified glassy carbon electrode capable of quantifying cesium (Cs) (93). Nickel hexacyanoferrate readily adsorbs $\mathrm{Cs}^{+}$and was utilized to preconcentrate $\mathrm{Cs}^{+}$ions at the electrode surface. While the limit of detection for the sensor was a fraction of a femptomolar, the useful analytical range was reported to be $\mathrm{pM}$ to $10 \mathrm{nM}$.

Kim and Amemiya reported the development of a sensor capable of sub-nanomolar detection of perchlorate in drinking water by casting a thin poly(vinyl chloride) (PVC) film on a poly(3-octylthiophene)-modified gold electrode, resulting in a fluid membrane (94). By using a thin PVC layer, the use of a redox mediator in the film was unnecessary. The detection limit for the resulting sensor was $0.55 \mathrm{nM}$ and was comparable to nonelectrochemical analytical techniques used to detect perchlorate.

\section{Analytes of Interest}

A large body of recent electrochemical research has focused on the detection of neuromessengers such as dopamine. Thus, a number of strategies for dopamine detection have been reported. Hermans and coworkers detailed a technique for quantifying dopamine using fast-scan cyclic voltammetry (95). This method typically suffers from high background currents in relation to the analyte signal. By combining the inverse of the prerecorded background current with the incoming analyte signal, real-time analog background subtraction was performed, allowing higher gains to be utilized. Principal component analysis was used to account for changes in the background so that measurements could be taken over a longer duration than previously possible with fast scan cyclic voltammetry. The authors demonstrated the use of this technique by following shortterm dopamine fluctuations in a rat brain after administration of cocaine.

Shang and colleagues reported the fabrication of a dopamine selective, boron-doped diamond (BDD) electrode modified via electropolymerization with an anion-doped poly $(N-$ acetyltyramine) and polypyrrole films (96). The anionic nature of the dopant, sulfobutylether- $\beta$-cyclodextrin, enhanced dopamine sensitivity and selectivity by both preconcentrating dopamine and excluding anionic interferences (i.e., ascorbic acid and uric acid). The resulting sensor exhibited a limit of detection for dopamine of $4-5 \mathrm{nM}$ and a response time of $1.5-2 \mathrm{~s}$. Deng and coworkers utilized boron-doped carbon nanotubemodified glassy carbon electrodes for the detection of dopamine (97). The boron-doped nanotubes resulted in a greater catalytic activity towards dopamine. The resulting sensors had detection limits for dopamine of $1.4 \mathrm{nM}$ with adequate peak separation to allow discrimination over ascorbic acid.

Özcan and Şahin described the fabrication of a graphite-based dopamine sensor that operates via adsorptive transfer stripping differential pulse voltammetry (98). The electrode was fabricated from pencil graphite that was first electrochemically treated via cyclic voltammetry. The limit of detection for dopamine was $0.31 \mathrm{nM}$, with no interference from uric acid. However, the sensor did exhibit a $20 \%$ increase in dopamine response in the presence of high concentrations of ascorbic acid $(100 \mu \mathrm{M})$, likely due to increased adsorption of dopamine. The authors tested the sensor in blood serum, reporting for the first time the successful electrochemical detection of dopamine (limit of detection of $2.9 \mathrm{nM}$ ) in undiluted blood with no pretreatment. 
Yan and coworkers fabricated a sensor capable of detecting 3,4-dihydroxyphenylacetic acid (DOPAC), a metabolite of dopamine, by functionalizing single-walled carbon nanotubes (SWCNTs) adsorbed on a glassy carbon electrode with cyclophane, a molecule with a strong binding affinity for DOPAC (99). Upon binding with the recognition element cyclophane, DOPAC was detected by cyclic voltammetry with high selectivity over both ascorbic acid and dopamine. The optimized sensor exhibited a linear range from the low $\mu \mathrm{M}$ level to 66 $\mathrm{mM}$, which could be tailored by varying the concentration of modified SWCNTs on the glassy carbon electrode.

Schreiber and coworkers reported a robust Clark-type microsensor with high spatial resolution for measurement of nitric oxide (NO) in biological milieu (100). The sensor was fabricated using a carbon fiber working electrode (30-40 $\mu \mathrm{m}$ dia), $\mathrm{Pt}$ anode, and $\mathrm{Ag} / \mathrm{AgCl}$ reference electrode encased in an electrolyte-filled glass casing sealed with a gas-permeable silicone membrane. The sensor was then used to measure NO from nitrifying biofilms and marine sediments, and proved ideal for use in environments where a rugged sensor is required. Shim and Lee developed a planar nanopore platinized Pt electrode for detecting NO release from surfaces with high spatial resolution (101). The sensor was fabricated by encasing a Pt wire in glass, etching to form a conical pore $(<1 \mu \mathrm{m}$ pore opening diameter, $30 \mu \mathrm{m}$ pore depth), platinization of the Pt surface, silanization of the pore walls, and electropolymerization of a NO-selective [poly(5-amino-1-naphthol)] film. The sensor exhibited a limit of detection for $\mathrm{NO}$ of $32 \mathrm{nM}$, and its utility was demonstrated in scanning electrochemical microscopy. Shin and coworkers developed a nitric oxide sensor composed of a fluorinated xerogel membrane coated on a platinized platinum microelectrode (102). The hydrophobicity of the membrane allowed for selective detection while excluding charged interfering species. The limit of detection for the sensor was $83 \mathrm{pM} \mathrm{NO}$, with limited response to common interfering species, such as nitrite, acetaminophen, ascorbic acid, and uric acid.

Ai and coworkers reported the fabrication of a hydrogen peroxide sensor via the deposition of platinum nanoparticles into Nafion pores on the surface of carbon fiber microdisk electrodes (103). The electrode exhibited a limit of detection of $5 \mathrm{nM}$. The authors utilized the sensor to make the first amperometric measurements of oxidative bursts from single plant protoplasts.

Hashemi and coworkers developed a sensor capable of in vivo detection of 5hydroxytryptamine (5-HT), a neurological signaling molecule (104). Carbon fiber electrodes usually suffer from fouling in live rat brains. The authors remedied the fouling problem via the addition of an electropolymerized layer of Nafion, which prevented the accumulation of 5-hydroxyindole acetic acid. The sensor was used to demonstrate the first successful electrochemical measurement of 5-HT in a living rat brain.

Hanson and colleagues utilized a mechanically ground pyrolytic graphite electrode to simultaneously detect analytes involved in the purine catabolism pathway (i.e., uric acid, xanthine, hypoxanthine) and drugs used to treat related disorders (i.e., allopurinol, and oxypurinol) (105). The concentration of each analyte was monitored via electrooxidation using differential pulse voltammetry. The clinical utility of the electrode was demonstrated by simultaneously measuring the five analytes in untreated urine of patients treated with allopurinol.

Wang and coworkers reported on a sensor capable of distinguishing between $o-, m-$, and $p$ aminophenol isomers (106). The sensor was fabricated by modifying a glassy carbon electrode with single-walled carbon nanotubes followed by electropolymerizing a coating of 4-aminopyridine on the surface. The resulting coating enhanced the electrocatalytic activity 
towards aminophenol isomers. The three isomers were distinguishable using cyclic voltammetry, with detection limits of 40,30 , and $60 \mathrm{nM}$ for $o-, m-$, and $p$-aminophenol, respectively.

\section{ELECTROCHEMICAL BIOSENSORS}

The field of electrochemical biosensors continues to expand based on affordable, simple, and highly selective and sensitive detection inherent with biological binding. Research in this field remains focused on novel sensing strategies with specific attention to the enhancement of specificity, limits of detection, and response time. The use of nanomaterials in the fabrication of electrochemical biosensors is widespread.

\section{Reviews}

Wang reviewed the principles of operation of electrochemical glucose biosensors, examining their history, recent developments and current status (107). In addition to elaborating on major strategies for enhancing their performance, the author describes key challenges and opportunities in their further development and use, with emphasis on fundamental advances of glucose sensing principles and related materials. Rather than providing a comprehensive review, Wang focuses on key developments and applications.

Lad et al. reviewed the recent developments on electrochemical creatinine biosensors (108). The authors introduced sensor design and analytical performance based on the recognition element and the nature of the transducer. Furthermore, they describe recent advances with enzyme-, antibody-, and molecularly imprinted polymer-based electrochemical sensors.

Song et al. summarized recent advances in the development of aptamer-based biosensors using electrochemical, optical, and mass-sensitive analytical techniques (109). In addition to describing general principles for each transduction mode, the authors also reviewed how the use of nanomaterials has improved the performance of aptamer-based sensors.

Hianik and Wang reviewed recent achievements in developing aptamer-based electrochemical biosensors (electrochemical aptasensors) (110). The authors discussed the configuration of aptamers and electrochemical methods for detecting aptamer-analyte interactions. A brief history of aptamer development is also provided, along with molecular structure, methods of aptamer engineering and aptamer immobilization chemistries.

Agui and Yanez-Sedeno reviewed recent advances in the development of new electrochemical sensors and biosensors that make use of carbon nanotube-modified electrodes (111). Specifically, they described the preparation of electrochemical biosensors, including enzyme electrodes, immunosensors and DNA biosensors, in which sensing performance was influenced by the carbon nanotubes. The review included discussion on the application of such sensors.

Pingarron et al. reviewed recent advances related to gold nanoparticle-based electrochemical biosensors (112). The operational characteristics of biosensors are highlighted with respect to non-nanostructured sensors. Electrochemical enzyme biosensors including those using hybrid materials with carbon nanotubes and polymers, sol-gel matrices, and layer-by-layer architectures are described. Similarly, the authors cover recent advances in the development of DNA biosensors and immunosensors using gold nanoparticles.

Sanvicens et al. reviewed the use of nanoparticle-based biosensors for pathogenic bacteria (113). In addition to motivation, the authors provided a general overview of the progress, limitations, and future challenges for nanoparticles-based devices. A variety of 
configurations were introduced, with particular focus towards point-of-care systems and multiplexed devices.

Jiang et al. provided an overview of various immunosensor transduction systems for pesticide detection (114). Antibody selection and immobilization protocols, regeneration, signal amplification, and miniaturization were discussed with attention to environmental and food analysis applications.

Palchetti and Mascini reviewed food pathogen detection methods based on electrochemical biosensors, with specific focus on amperometric, potentiometric, and impedimetric devices (115). The underlying principles and application of the biosensors were introduced. Emphasis was given to new biorecognition elements, the use of nanomaterials, and lab-on-achip technologies.

Lastly, Walcarius and Collinson provided a review on silica sol-gels in analytical chemistry with a wide-range of examples from separation science, optical and electrochemical sensors (116). This review focused on the importance of manipulating the structure and composition of these materials at different scales (e.g., from molecular to macromolecular states and/or from micro- to meso- and/or macroporous levels) to generate chemical and biochemical sensing devices with improved selectivity and sensitivity.

\section{Enzyme Biosensors}

Research related to enzyme-based biosensors continued to be published, but at a somewhat slower rate compared to 2006 - 2007. A significant amount of the published work encompassed the use of nanomaterials in biosensor construction. For instance, Vamvakaki et al. reported the synthesis of silica and conductive activated carbon nanofibers (CNFs) that were then used in a synergistic manner to develop an electrochemical biosensor (117). The sensor was fabricated by encapsulating an enzyme with poly(L-lysine)-templated silica, resulting in a stable environment for the enzyme even in harsh conditions (i.e., high temperatures and in the presence of proteases). Lopez et al. reported the fabrication of a biosensor using tyrosinase (Tyr)-integrated carbon nanotube (CNT) epoxy composite electrodes (CNTECE) to measure catechol (118). The use of CNTs improved the electronic transference between the enzyme and the electrode surface. The MWCNT-based catechol biosensor exhibited a linear response from $0.01-0.15 \mathrm{mM}$.

The development of glucose biosensors has been a focus of significant research due to their for diabetes management. As the incidence of diabetes has increased, new glucose sensors continue to be developed. For example, Fu et al. constructed amperometric glucose biosensors using chemical preoxidation and electropolymerization of monomers (CPEM) in enzyme-containing aqueous solutions (119). Oligomer composites containing glucose oxidase (GOx) or alkaline phosphatase (ALP) were electrochemically co-deposited with poly(1,4-benzenedithiol) on an Au electrode, yielding an enzyme film with high enzyme loading and activity. The glucose biosensor prepared using the CPEM protocol showed improved sensitivity over the more conventional (preoxidant-free electropolymerization) protocol.

Rowinski and coworkers reported the preparation of amperometric glucose biosensor membranes using thermodynamically stable cubic phase lyotropic liquid crystals (LLCs) (120). The resulting membranes contained three-dimensionally interconnected water channels of uniform diameter, resulting in reproducible glucose transport-characteristics.

Gopalan et al. fabricated a glucose biosensor by loading GOx within an organic-inorganic hybrid nanocomposite (121). Briefly, the preparation involved formation of a silica/Nafion 
network into which polyaniline-grafted multi-walled carbon nanotubes (MWNT-g-PANI) on Nafion-silica nanocomposites were loaded. The Nafion-silica/MWCNT-g-PANI/GOx biosensor exhibited a linear response to glucose from $1-10 \mathrm{mM}$, fast response, and longterm stability.

Barbadillo et al. described the synthesis of an organic-inorganic hybrid composite material for glucose sensing (122). The material was prepared by entrapping both gold nanoparticles and GOx into a sol-gel matrix containing graphite (to impart conductivity). When applied to the determination of glucose in the presence of hydroxymethylferrocene redox mediator, the sensor exhibited electrocatalytic activity towards glucose at a working potential of $+250 \mathrm{mV}$ versus $\mathrm{Ag} / \mathrm{AgCl}$.

Ciobanu and coworkers reported the fabrication of ultramicroelectrode (UME) biosensors for glucose and lactate based on glucose oxidase and lactate oxidase, respectively (123). The glucose UME biosensor was used to record profiles of glucose uptake above individual fibroblasts via scanning electrochemical microscopy. Likewise, the lactate UME biosensor was employed to record the lactate production above single cancer cells.

Amperometric adenosine triphosphate (ATP) microbiosensors were fabricated by Masson et al. to characterize the stimulus-response at rat carotid bodies superfused with potassium during normoxic hypercapnia and hypoxia (124). Glucose oxidase and hexokinase were immobilized within a sensor membrane coated onto Pt disk microelectrodes ( $25 \mu \mathrm{m}$ dia.). The ATP microbiosensor response was linear from 0 to $40 \mu \mathrm{M}$ ATP enabling quantitative detection of ATP released at the carotid body surface in response to physiological stimuli. Other electroactive neurotransmitters (e.g., catecholamines) were simultaneously detected utilizing a dual-electrode assembly with an ATP microbiosensor and a second bare channel providing a co-localized reference measurement for ATP quantification.

Peng and colleagues reported the construction of an amperometric trace hydrogen peroxide sensor composed of a mixed monolayer of ferrocenylalkanethiol and encapsulated horseradish peroxidase (HRP) (125). Unlike most HRP-based electrochemical sensors that rely on HRP-facilitated hydrogen peroxide reduction, the electrocatalytic current was attributed to an HRP-catalyzed oxidation reaction of hydrogen peroxide. The limit of detection of the sensor was $0.64 \mathrm{nM}$ hydrogen peroxide over a dynamic range spanning $>3$ orders of magnitude. The authors attributed the enhanced activity to the encapsulation that preserved the native structure of HRP.

El Ichi et al. described a mediator-free phenol biosensor using POX1B, a garlic-derived protein with similar biochemical properties to peroxidase, encapsulated in chitosan(126). The redox potential of POX1B in chitosan was $147 \mathrm{mV}$ vs. SCE, significantly greater than for HRP, demonstrating excellent direct electrochemical behavior. The biosensor was responsive to chlorophenol derivatives from $10 \mathrm{pM}$ to $10 \mu \mathrm{M}$, with a detection limit for 4chlorophenol of $1 \mathrm{pM}$.

Deng and coworkers reported on a superoxide anion biosensor based on direct electron transfer of copper, zinc-superoxide dismutase (Cu, Zn-SOD) at zinc oxide nanodisks for in vivo monitoring of superoxide in bean sprouts (127). The combination of facilitated direct electron transfer and bifunctional enzymatic catalytic activities allowed for cathodic determination of superoxide $(0 \mathrm{mV} v \mathrm{Ag} / \mathrm{AgCl})$ with high selectivity over a wide linear range. The electrode response due to common interfering species (e.g., hydrogen peroxide, uric acid, ascorbic acid, and 3,4-dihydroxyphenylacetic acid) was thus avoided.

The effect of introducing positive charges (lysines) in human cytochrome c (cyt c) on the redox properties and reaction rates of cyt $\mathrm{c}$ with superoxide radicals was reported by 
Wegerich et al (128). The mutated forms of this electron-transfer protein were used as sensorial recognition elements for the amperometric detection of reactive oxygen radicals. Some of the mutants showed a higher reaction rate with the radical as compared to wild type. These mutants were used for the construction of superoxide sensors based covalently fixed proteins to thiol-modified gold electrodes.

Jamal and coworkers reported the fabrication of a glutamate oxidase-modified platinum electrode for determining alanine aminotransferase (ALT) activity based on detection of Lglutamate (129). Interference from ascorbic acid and uric acid was eliminated using background subtraction at a denatured glutamate oxidase enzyme electrode. The linear range of the sensor was reported to be $10-1000 \mathrm{U} / \mathrm{L}$ with a LOD of $3.29 \mathrm{U} / \mathrm{L}$ at a working potential of $+0.4 \mathrm{~V}$ vs. $\mathrm{Ag} / \mathrm{AgCl}$.

Lin et al. reported the fabrication of an electrochemiluminescent (ECL) biosensor based on an electrically heated carbon paste electrode modified with xanthine oxidase (XOD) (130). The ECL intensity of luminol was enhanced by adding hypoxanthine (HX) to the solution. The biosensor response proved to be sensitive to temperature. As such, a constant temperature for the XOD/HCPE was necessary to achieve the optimal ECL signal.

So and coworkers reported on sensors that measure DNA damage from metabolism of arylamines (131). The sensors were fabricated by coating pyrolytic graphite electrodes with ultrathin films containing DNA and N-acetyltransferase (NAT), an enzyme that catalyzes the conversion of the arylamine 2-aminofluorene to 2-acetylaminofluorene (2-AAF). DNA damage from reactive 2-AAF metabolites was measured subsequent to the enzyme reaction using catalytic voltammetric oxidation with $\mathrm{Ru}(\mathrm{bpy}){ }_{3}{ }^{2+}$. DNA damage occurred more rapidly under weakly acidic conditions ( $\mathrm{pH} 5.5-5.8)$ than neutral $\mathrm{pH}$, suggesting that genotoxicity from arylamine metabolism by NAT may be more significant in slightly acidic environments.

\section{DNA Sensors}

Aptamers have been employed in the design of novel biosensors (i.e., aptasensors) due to their inherent selectivity, affinity, and multifarious advantages over traditional recognition elements. DNA sensors are generally divided into two categories: (1) sensors that detect specific DNA sequences, and (2) sensors that use DNA fragments to bind and detect nonDNA molecules (i.e., small molecules and proteins). Both types are addressed below.

Lubin et al. studied the effects of probe length, probe geometry, and redox-tag placement on reagentless, electrochemical DNA (E-DNA) sensors (132). Electrochemical DNA sensors were fabricated using linear or stem-loop probes of various lengths with redox tags placed either distal to the electrode or internally within the probe sequence (proximal). Linear probes produced larger signal changes upon target binding than equivalent stem-loop probes. Likewise, long probes exhibited greater signal changes vs. short probes, provided that the redox tag was placed proximal to the electrode surface. In contrast to their improved signaling, the specificity of long probes was poorer than that of short probes, suggesting that sensor optimization represents a trade off between sensitivity and specificity.

Wu et al. described a signal amplification strategy for electrochemical detection of DNA and proteins based on amplification-by-polymerization (133). After capture of target molecules on the electrode surface, a controlled radical polymerization reaction was initiated. Growth of long chain polymeric materials provided numerous sites for subsequent aminoferrocene coupling, which in turn enhanced the electrochemical signal output. A limit of detection of $15 \mathrm{pM}$ and $0.07 \mathrm{ng} / \mathrm{mL}$ was demonstrated for DNA and ovalbumin, respectively. 
Furthermore, a 7-fold signal enhancement in ovalbumin detection was achieved relative to control (unamplified) sensors.

A hybridization-based disposable electronic DNA biosensor for the detection of a functional polymorphism in the catechol- $O$-methyl transferase (COMT) gene from polymerase chain reaction (PCR) amplicons was reported by Ozkan-Ariksoysal and coworkers (134). Short synthetic oligonucleotides and PCR amplicons were used to measure the change of guanine oxidation obtained after DNA hybridization between the probe and target (synthetic target or denatured PCR samples). The detection limit of the biosensor was 2.44 pmol of target sequence in the $30 \mu \mathrm{L}$ samples.

Zhang et al. modified a glassy carbon electrode with vertically-assembled carboxylic groupfunctionalized single-walled carbon nanotubes (SWNTs), and then wrapped the SWNTs with single-stranded DNA (ssDNA) complimentary to the target DNA (135). The hybridization of the target and complimentary ssDNA into double-stranded DNA (dsDNA) reduced the number of electrooxidizable guanidine sites, decreasing the measured current. Under optimum conditions, the plot of current (guanine bases) versus complimentary DNA concentrations was linear between $40-110 \mathrm{nM}$ with a detection limit of $20 \mathrm{nM}$.

Zhang et al. described an electronic DNA biosensor for simple, rapid, and specific detection of nucleic acids based on a proximity-dependent surface hybridization assay (136). The EDNA biosensor was constructed by self-assembly of a $3^{\prime}$ short thiolated $5^{\prime}$ ferrocene $(\mathrm{Fc})$ labeled capture probe on a gold electrode. DNA detection was achieved by measuring the redox current of the $5^{\prime} \mathrm{Fc}(\mathrm{Fc})$ tail-labeled probe upon binding of a complimentary ssDNA. The E-DNA biosensor was characterized as having a low detection limit (1 fM) and wide dynamic range (fM to $\mathrm{nM}$ ).

Chen and coworkers fabricated a sensor capable of detecting chronic myelogenous leukemia (CML) DNA by immobilizing an acridone derivative 2-nitroacridone (NAD) on a glassy carbon electrode (137). Single-stranded CML DNA fragments were then used to further modify the electrode. The sensor was characterized as having a detection limit of $6.7 \mathrm{nM}$ and a linear response range of $18 \mathrm{nM}-91 \mathrm{nM}$ for complimentary CML DNA.

Chen et al. reported the fabrication of an electrochemical DNA biosensor for detection of the breakpoint cluster region gene and the cellular abl (BCR/ABL) fusion gene of CML by using single-stranded DNA as the capture probe (138). The capture probe was covalently attached to a sulfonic-terminated aminobenzenesulfonic acid monolayer-modified glassy carbon electrode. Differential pulse voltammetry was used to monitor the hybridization reaction on the capture probe electrode, resulting in a sensor with a linear range of $1.0-11$ $\mathrm{pM}$ and a detection limit of $0.94 \mathrm{pM}$. Overall, the method demonstrated excellent specificity for single-base mismatches.

Xiao and coworkers reported on a sensor that enables single-step, room-temperature single nucleotide polymorphism detection directly in complex samples (e.g., blood serum) without the need for target modification, postwashing, or the addition of exogenous reagents (139). The reusable sensor was comprised of a single, self-complementary, methylene blue-labeled DNA probe possessing a triple-stem structure. The discrimination capabilities of this sensor greatly exceed those of earlier single- and double-stem electrochemical sensors, and support rapid (minutes), single-step, reagentless, room-temperature detection of single nucleotide substitutions.

$\mathrm{Hu}$ et al. reported the fabrication of a DNA sensor using a nanoporous gold (NPG) electrode and multifunctional encoded Au nanoparticles (AuNP) (140). The electrode was first modified with capture probe DNA, then hybridized with target DNA, and further hybridized 
with the reporter DNA loaded on the AuNPs. The resulting sensor exhibited a linear range of $80 \mathrm{aM}-1.6 \mathrm{pM}$, with a limit of detection as low as $28 \mathrm{aM}$ and excellent selectivity even for single-mismatched DNA detection.

$\mathrm{Wu}$ and colleagues reported the use of a low-volume solid-contact silver ion-selective $\left(\mathrm{Ag}^{+}-\right.$ ISE) electrode to monitor the depletion of silver ions induced by the biocatalytic reaction of an alkaline-phosphatase enzyme tag employed in DNA hybridization. The resultant potential change of the $\mathrm{Ag}^{+}$-ISE served as the hybridization signal. The resulting sensor was characterized by a detection limit of $50 \mathrm{fM}(0.2 \mathrm{amol})$ DNA target.

Swensen et al. reported on the fabrication of a microfluidic electrochemical aptamer-based sensor chip wherein target-specific DNA aptamers fold in response to an analyte, thus generating an electrochemical signal (141). As a model, cocaine was used to demonstrate the continuous, real-time (similar to 1 min time resolution) detection of a small molecule at low micromolar concentrations directly in undiluted, unmodified blood serum. The integration of folding-based electrochemical sensors with miniaturized detection systems may enable realtime, point-of-care detection of a wide variety of molecular targets in unprocessed samples.

Deng et al. reported the fabrication of a bifunctional electrochemical sensor for detection of small molecules and proteins (i.e., adenosine and lysozyme, respectively) (142). Two aptamer units for adenosine and lysozyme were immobilized on the gold electrode along with DNA-modified gold nanoparticles. The detection of adenosine or lysozyme was then determined by switching the DNA/DNA duplex to a DNA/target complex. The resulting aptasensor was characterized as having a low detection limit $(0.02 \mathrm{nM}$ for adenosine and $0.01 \mu \mathrm{g} / \mathrm{mL}$ for lysozyme), high sensitivity and bifunctional recognition.

Zhang and coworkers also developed an electrochemical sensing strategy for sensitive detection of small molecules based on analogous switching structures (143). In the presence of adenosine, aptamer bound adenosine folded, releasing pre-immobilized reporter probes and gold nanoparticles (AuNPs) into solution, resulting in a decrease in peak current. With the enhancement by AuNPs, a detection limit as low as $180 \mathrm{pM}$ for adenosine was achieved.

Cash et al. demonstrated a general, sensitive, and selective approach for the detection of macromolecules that bind to small molecule recognition elements (144). The DNA sensor was fabricated by immobilizing a redox-tagged DNA signaling scaffold conjugated to a small molecule recognition element on a working electrode. Upon binding of target small molecules, the availability of the redox-tagged DNA to the electrode surface changed, altering the observed current. Sensors for two targets (streptavidin and anti-digoxigenin) were fabricated and characterized as having detection limits in the low nanomolar range and adaquate selectivity to operate in complex matrices such as blood serum, soil, and food.

Sun and coworkers reported the fabrication of a general biosensor based on the immobilization of hemoglobin $(\mathrm{Hb})$ on a Nafion and DNA-modified carbon ionic liquid electrode (145). As characterized by a pair of well-defined redox peaks, the Nafion and DNA composite film provided an excellent microenvironment for maintaining the native structure of $\mathrm{Hb}$ and promoting the direct electron transfer rate of $\mathrm{Hb}$ with the basal electrode. The electrochemical biosensor showed good electrocatalytic response to the reduction of trichloroacetic acid, $\mathrm{H}_{2} \mathrm{O}_{2}, \mathrm{NO}_{2}^{-}$.

Du et al. fabricated a multifunctional reusable label-free electrochemical biosensor using an integrated aptamer for parallel detection of adenosine triphosphate (ATP) and alphathrombin (146). A gold electrode was modified with a DNA duplex containing a $5^{\prime}$-thiolated complementary strand, and a mixed aptamer containing both a small-molecule ATP binding 
aptamer and a protein alpha-thrombin binding aptamer. The detection limits for the resulting sensor were $10 \mathrm{nM}$ and $10 \mathrm{pM}$ for ATP and alpha-thrombin, respectively.

Ricci et al. reported a reagentless, electrochemical platform for the specific detection of proteins that bind to single- or double-stranded DNA (147). The sensor was composed of a double- or single-stranded, redox-tagged DNA probe covalently attached to an interrogating electrode. Upon protein binding, the current arising from the redox tag was suppressed, indicating the presence of the target. Using this approach sensors were fabricated against, TATA-box binding protein, M. HhaI methyltransferase, Escherichia coli single strand binding protein, and replication protein A. Detection at the sensor was demonstrated for the four proteins at nanomolar concentrations. The approach was highly specific with no observation of cross-reactivity between the sensors.

Ghanbari et al. reported a biosensor in which DNA was immobilized on a nano-structured conductive polymer fixed onto a platinum electrode (148). The sensor was fabricated by adsorbing double-stranded DNA onto the polypyrrole nanofiber (30-90 nm in diameter)modified electrode. For the determination of spermidine, the proposed method exhibited good binding (binding constant of $\left.4.08 \times 10^{5} \pm 0.05 \mathrm{M}^{-1}\right)$, and a low detection limit $(0.02$ $\mu \mathrm{M})$, although $\mathrm{Ca}^{2+}$ ions were found to electrostatically bind to DNA and weaken the spermidine-DNA interaction.

\section{Immunosensors}

(a) Bacteria, Viruses, and Cancer Biomarkers-Immunosensors are well suited for aiding in the diagnosis of disease due to their high target specificity, rapid detection, and simple, inexpensive fabrication and operation. Abu-Rabeah et al. developed a disposable amperometric Escherichia coli (E. coli) immunosensor using a polypyrrole-NH2-anti-E. coli antibody-modified electrode coating with an alginate-polypyrrole packing layer (149). The advantages of this immunosensor included an improved detection limit and simple sample treatment.

Escamilla-Gomez and coworkers developed a Staphylococcus aureus (S. aureus) amperometric immunosensor based on the covalent immobilization of antibodies at gold electrodes via heterobifunctional cross-linkers (3,3-dithiodipropionic acid di( $\mathrm{N}$-succinimidyl ester, DTSP) (150). Sensor response was the result of tetrathiafulvalene as a redox mediator entrapped at the electrode surface. Gold screen-printed electrodes were used to develop disposable immunosensors with a limit of detection of $3.7 \times 10^{2}$ cells $/ \mathrm{mL}$ and a dynamic range from $1.3 \times 10^{3}$ to $7.6 \times 10^{4}$ cells $/ \mathrm{mL}$.

Matzila et al. reported the development of a faradic impedimetric immunosensor for the detection of $S$. typhimurium in milk (151). Polyclonal Salmonella antibodies were crosslinked onto amino- and alcohol-self-assembled monolayer-modified gold electrodes using glutaraldehyde. Signal amplification was achieved by performing the immunoreaction directly in culture samples. The analytical utility of the immunosensors was demonstrated by measuring $S$. typhimurium in inoculated milk samples. Similarly, Pournaras et al. employed electropolymerized polytyramine films and cross-linked polyclonal Salmonella antibodies to measure $S$. typhimurium (152). Faradic electrochemical impedance spectroscopy in the presence of a hexacyanoferrate(II)/(III) redox couple was utilized to measure bacteria concentrations in milk. The limit of detection of the immunosensor was $10 \mathrm{cfu} / \mathrm{mL} S$. typhimurium.

Salam and Tothill fabricated a chronoamperometric immunosensor capable of rapid $S$. typhimurium detection based on a screen-printed gold working electrode with onboard carbon counter and silver-silver chloride pseudo-reference electrodes (153). Both physical 
and covalent immobilizations via amines were used to couple the $S$. typhimurium antibody to carboxymethyldextran on the surface of the gold working electrode. A direct sandwich enzyme-linked immunosorbent assay format was carried using polyclonal anti-Salmonella antibodies conjugated to horseradish peroxidase as the enzyme label and $3,3^{\prime}, 5,5^{\prime}$ Tetramethylbenzidine dihydrochloride (TMB) $/ \mathrm{H}_{2} \mathrm{O}_{2}$ as the enzyme mediator/substrate system. S. typhimurium detection of $5 \times 10^{3}$ cells $/ \mathrm{ml}$ to $20 \mathrm{cells} / \mathrm{ml}$ was achieved for physical and covalent antibody immobilization, respectively.

Mwilu et al. reported the identification and quantification of Bacillus globigii, a spore forming nonpathogenic simulant of Bacillus anthracis, via a label-free, metal-enhanced electrochemical immunosensor (154). Bacillus globigii (BG) antibodies were immobilized on a gold quartz crystal electrode through cystamine coupling. A solid-phase monolayer of silver on top of the cystamine modified-Au-electrode surface was used as the redox probe. When the antibody-modified electrode was exposed to BG spores, the antibody-antigen complex insulated the electrode surface toward the silver redox probe. The variation of redox current was proportional to the concentration of the BG spores between $1 \times 10^{2}-3.5$ $\times 10^{4}$ spores $/ \mathrm{mL}$ with a detection limit of 602 spores $/ \mathrm{mL}$.

Labib and coworkers used a flow-injection capacitive immunosensor based on selfassembled monolayers to measure cholera toxin (CT) (11). Monoclonal antibodies against the B subunit of CT (anti-CT) were immobilized on a gold electrode. The immunosensor responded linearly to CT concentrations from $0.10-100 \mathrm{pM}$ with a limit of detection of 10 fM. The capacitive immunosensor had a greater sensitivity than both sandwich enzymelinked immunosorbent assay (ELISA) and surface plasmon resonance (SPR).

Nguyen et al. fabricated a membrane-based electrochemical nanobiosensor that was sensitive to whole viral particles (155). Antibody probe molecules were physically adsorbed onto the walls of membrane nanochannels prepared by casting a submicrometer thick nanoporous alumina membrane on a platinum disk electrode. Sensor response was based on the faradaic current from ferrocenemethanol. The detection of viral particles was logarithmically linear up to $53 \mathrm{pg} / \mathrm{mL}$ and 50 viral particles per $100 \mathrm{~mL}$ in $\mathrm{pH} 7$, with detection limits of $4 \mathrm{pg} / \mathrm{mL}$ and ca. 2 viral particles per $100 \mathrm{~mL}$. The advantages of the sensor over conventional PCR analysis included its simple fabrication, minimal sample preparation, and short detection time (30 $\mathrm{min})$.

Wang et al. reported the development of an impedance immunosensor using an interdigitated array (IDA) microelectrode for sensitive, specific and rapid detection of avian influenza (AI) virus H5N1 (156). Polyclonal antibodies against AI virus H5N1 surface antigen HA (hemagglutinin) were oriented on the gold microelectrode surface through protein A. A change in the impedance of the IDA microelectrode surface was measured upon capture of target H5N1 viruses. Red blood cells were used as biolabels for further amplification of the binding reaction of the antibody-antigen (virus). The response of the antibody-antigen (virus) interaction was shown to be virus titer-dependent, and a linear range for the titer of H5NI virus was found between $10^{3}$ and $10^{7}$ EID50/ml.

Barton et al. described methods for immobilizing antibodies for prostate specific antigen (APSA) using ac impedance (157). Microelectrode array sensors were fabricated using an affinity approach (i.e., immobilization of a biotinylated APSA using a classical avidin-biotin affinity approach) exhibited detection limits 1000 times lower than those formulated by entrapment (i.e., APSA entrapment during electropolymerization of the polyaniline). This demonstrated that assembly protocols have major effects on immunosensor performance.

Kurtinaitiene fabricated an amperometric immunosensor for detecting antibodies against bovine leukemia protein (gp51) (158). The antibody-antigen complex formation was 
determined through the use of mediators (ferrocenecarboxylic acid (FCA) and $\mathrm{N}, \mathrm{N}, \mathrm{N}^{\prime}, \mathrm{N}^{\prime}$ tetramethylbenzidine) and secondary antibodies labeled with horseradish peroxidase (HRP). The sensitivity of the sensor was comparable with enzyme-linked immunosorbent assay (ELISA) and agar gel immunodiffusion.

Zhang and coworkers fabricated a reusable amperometric immunosensor based on a reversible boronic acid-sugar interaction (159). The analytical measurement consisted of the specific binding of carcinoembryonic antigen (CEA) with enzyme-conjugated antibody. After the formation of the immunocomplex, the access of the active center of horseradish peroxidase (HRP) to thionine was partially inhibited resulting in a linear decrease in the electrocatalytic response of HRP-anti-CEA-modified electrode over a CEA concentration range of 2.5 to $40.0 \mathrm{ng} / \mathrm{mL}$. The limit of detection for CEA was reported as $1.1 \mathrm{ng} / \mathrm{mL}$.

(b) Agriculture-Liu et al. reported the fabrication of an ochratoxin A (OTA) immunosensor in an indirect competitive assay format (160). The sensing substrate was prepared using a gold electrode modified with a 1,6-hexanedithiol self-assembled monolayer that mediated the assembly of a gold colloid layer to enhance the surface loading of OTAovalbumin conjugates and improve sensitivity. The competition between anti-OTA mouse monoclonal antibody and OTA analyte in sample solution resulted in an electrochemical response upon subsequent binding of alkaline phosphatase-labeled horse anti-mouse immunoglobulin $\mathrm{G}$ antibody. Electrochemical response (arising from the oxidation of enzymatic product of 1-naphthyl phosphate) was inversely proportional to OTA concentration in the range from $10 \mathrm{pg} / \mathrm{ml}$ to $100 \mathrm{ng} / \mathrm{ml}$ with a detection limit of $8.2 \mathrm{pg} / \mathrm{ml}$.

March et al. developed a quartz crystal microbalance immunosensor to measure carbaryl and 3,5,6-trichloro-2-pyridinol (TCP), the primary metabolites of the insecticide chlorpyrifos and herbicide triclopyr (161). Detection of the analytes was achieved using monoclonal antibodies in a competitive conjugate-immobilized immunoassay. Hapten conjugates were covalently immobilized onto the gold electrode sensitive surface of the quartz crystal using a thioctic acid SAM, allowing for reusability for at least one hundred and fifty assays. The detection limits of the piezoimmunosensor were 11 and $7 \mu \mathrm{g} / \mathrm{L}$ for carbaryl and TCP, respectively.

Ramon-Azcon et al. fabricated an antibody impedimetric immunosensor for measuring atrazine pesticide (162). An atrazine-haptenized protein was covalently immobilized on the surface of interdigitated micro-electrodes area previously activated with (3-

glycidoxypropyl)trimethoxysilane. Immunosensor measurements were carried out by exposing the sensor to solutions containing a mixture of the analyte and the specific antibody. The limit of detection of the sensor was $0.04 \mu \mathrm{g} / \mathrm{L}$ without the use of label.

Nassef and coworkers reported on the development of gliadin immunosensor using antigliadin Fab fragment (CDC5-Fab)-modified gold electrodes (163). Both impedance and amperometry were used to determine gliadin concentrations. While the limit of detection for label-less impedimetric detection was $0.42 \mu \mathrm{g} / \mathrm{mL}$, the amperometric immunosensor based on Fab fragments was more sensitive with a limit of detection of $3.29 \mathrm{ng} / \mathrm{mL}$. In addition to sensitivity, the advantages of the Fab-based immunosensor included easy fabrication and fast assay time.

Nassef et al. also reported on an electrochemical immunosensor for measuring the gliadin content and potential celiac toxicity of food (164). Two dithiol linkers (2,2-(3,5-bis((6mercaptohexyl)oxy)phenyl)-3,6,9,12,15,18,21-heptaoxadocos anoic acid and 1,2dithiolane-3-pentanoic acid) were evaluated as anchors for the capture antibody. The heptaoxadocosanoic acid surface proved superior with a $5.5 \mathrm{ng} / \mathrm{ml}$ limit of detection, 
nonspecific binding of $2.7 \%$ of the specific signal attained, and excellent reproducibility. The utility of the immunosensor was demonstrated in the analysis of commercial gluten-free and gluten-containing raw and processed food.

Pividori and colleagues designed an electrochemical immunosensor for the detection of antibodies to tissue transglutaminase (tTG) in human serum (165). Graphite-epoxy composite electrodes were modified with tTG. After reaction with human serum (containing the specific antibodies in the case of celiac disease), the electrode was incubated with horseradish peroxidase-conjugated goat secondary antibodies to whole human $\operatorname{IgC}$ or $\operatorname{Ig} \mathrm{A}$ to generate the electrochemical response.

(c) Other Analytes-Giroud fabricated an impedimetric immunosensor for the label-free detection of ciprofloxacin, an antibiotic belonging to synthetic fluoroquinolones (166). A poly(pyrrole-N-hydroxysuccinimide) film was electrogenerated onto an electrode and then used to covalently bind fluoroquinolone bearing an amino group. The resulting electrode was utilized to immobilize a layer of anticiprofloxacin antibody onto the polymer surface via immunoreaction. In the presence of ciprofloxacin, the antibody was displaced in solution inducing changes in the impedance of the sensor electrodes. Sensors exposed to ciprofloxacin showed a decrease in the sum of the interfacial resistances with the increase in ciprofloxacin concentration from $1 \mathrm{pg}$ to $1 \mu \mathrm{g} / \mathrm{mL}$.

Koh et al. reported a solid-state potentiometric immunosensor to evaluate neuronal nitric oxide synthase (nNOS) activity (167). A $\mathrm{H}^{+}$-selective ISE was fabricated with a carboxylated poly(vinyl chloride) (PVC-COOH) film containing $\mathrm{H}^{+}$ionophore. Antibody was then immobilized on the polymer layer. The immunocomplex formation was detected by monitoring $\mathrm{pH}$ change due to interaction between urease-labeled secondary antibody and antigen. The detection limit of nNOS was determined to be $0.2 \mu \mathrm{g} / \mathrm{ml}$.

Kwon et al. reported on a new redox cycling scheme using nicotinamide adenine dinucleotide (NADH) for signal amplification of mouse IgG biosensors in the absence of diaphorase enzyme (168). In a sandwich immunosensor format, an alkaline phosphatase label was used to convert $\mathrm{p}$-aminophenylphosphate (APP) into electroactive p-aminophenol (AP). The amplified AP was oxidized to p-quinoneimine (QI) by electrochemically generated ferrocenium ion (via a partially ferrocenyl-tethered dendrimer layer. NADH reduced QI back to AP, which then could be re-oxidized. This redox cycling enabled a low detection limit for mouse $\operatorname{IgG}(1 \mathrm{pg} / \mathrm{mL})$.

Prabhulkar et al. reported the fabrication of a sensitive, reagentless biosensor for the detection of vascular endothelial growth factor (VEGF) (169). Ferrocene monocarboxylic acid labeled anti-VEGF was covalently immobilized on carbon fiber microelectrodes. The formation of immuno-complexes decreased the electrochemical signal of ferrocene monocarboxylic acid by spatial blocking of the microelectrode surface, enabling quantitative detection of VEGF in solution. The immunosensing strategy allowed rapid and sensitive VEGF analysis with a limit of detection of about $38 \mathrm{pg} / \mathrm{mL}$.

Preechaworapun et al. reported the fabrication of an amperometric protein immunosensor at boron-doped diamond (BDD) electrodes (170). The carboxyl groups of o-aminobenzoic acid electropolymerized electrode were used to covalently attach protein probes. Quantitative analysis of mouse $\operatorname{IgG}(\mathrm{MIgG})$ was achieved using a sandwich-type alkaline phosphatase (ALP) catalyzing amperometric immunoassay with 2-phospho-L-ascorbic acid (AAP) as substrate. The current was proportional to the quantity of MIgG in solution with limits of detection (LODs) of $0.30 \mathrm{ng} / \mathrm{mL}$ for MIgG at BDD electrodes. 
$\mathrm{Qu}$ and coworkers reported a micro-potentiometric hemoglobin $(\mathrm{Hb})$ immunosensor using a gold nanoparticle-modified polypyrrole (AuNP-PPy) composite film (171). The AuNPs facilitated antibody immobilization onto the electrode surface. A micro-potentiometric immunosensor for $\mathrm{Hb}$ and hemoglobin-A1c $(\mathrm{HbA} 1 \mathrm{c})$ was constructed using an integrated chip containing ion-sensitive field-effect transistors. The sensor response in blood was linear over $60-180 \mu \mathrm{g} / \mathrm{ml} \mathrm{Hb}$ and $4-18 \mu \mathrm{g} / \mathrm{ml} \mathrm{HbA1c}$ with a sensitivity of $0.20 \mathrm{mV} \mu \mathrm{g} / \mathrm{ml}$.

Singh et al. fabricated an amperometric immunosensor for the detection of osteoproteogerin (OPG) by covalently immobilizing a monoclonal OPG antibody (anti-OPG) onto a gold nanoparticle (AuNP)-functionalized conducting polymer $\left(5,2^{\prime}: 5^{\prime}, 2^{\prime \prime}\right.$-terthiophene- $3^{\prime}$ carboxylic acid) (14). A competitive immunoassay between free-OPG and labeled-OPG for the active sites of anti-OPG was employed. The catalytic reduction of hydrogen peroxide via horseradish peroxidase (label) was monitored amperometrically. The immunosensor showed a linear response between 2.5 and $25 \mathrm{pg} / \mathrm{ml}$ and detection limit of $2 \mathrm{pg} / \mathrm{mL}$.

(d) Nanomaterials-As with other sensors, the vast majority of recent immunosensor research has focused on the exploitation of the unique properties of nanomaterials (i.e., nanostructured surfaces, nanoparticles, and nanotubes) to enhance the performance of such sensors. Barton et al. reported the fabrication of a label-less immunosensor for neuronspecific enolase (NSE) using ac impedance (172). Poly(1,2-diaminobenzene)-modified carbon electrodes were sonochemically ablated to form an array of micropores. A second electropolymerization step was then used to deposit conductive polyaniline within these pores to give a microarray of polyaniline protrusions with diameters of several $\mathrm{pm}$. The array was utilized as a substrate to immobilize a biotinylated antibody for NSE using a classical avidin-biotin approach. The real component of the impedance of the electrodes increased with antigen concentration $(0$ to $50 \mathrm{pg} / \mathrm{mL}$. Calibration curves obtained by subtraction of the responses for specific and nonspecific antibody-based sensors eliminated the effects of nonspecific adsorption of NSE.

Chen and coworkers developed a label-free immunosensor for the detection of C-reactive protein (CRP) using a three-dimensional ordered macroporous (3DOM) gold film-modified electrode and impedance spectroscopy (173). The electrode was electrochemically fabricated with an inverted opal template, increasing the surface area of the 3DOM gold electrode. The CRP concentration was measured through the increase of impedance values in the corresponding specific binding of CRP antigen and CRP antibody. The increased electron-transfer resistance (R-et) values were proportional to the logarithmic value of CRP concentrations in the range of 0.1 to $20 \mathrm{ng} / \mathrm{mL}$.

Bangar et al. reported on a conducting polymer nanowire-based biosensor (174). Polypyrrole (Ppy) nanowires were synthesized by electrochemical polymerization using an alumina template. The single-nanowire chemoresistive sensor device was assembled on a pair of gold electrodes separated. $N$-(3-dimethylaminopropyl)- $N^{\prime}$-ethylcarbodiimide hydrochloride chemistry was used to surface-functionalize a single Ppy nanowire with cancer antigen (CA 125), resulting in a nanoimmunosensor for $\mathrm{CA} 125$ biomarker analysis. The immunosensor had excellent sensitivity with a detection limit of $1 \mathrm{U} / \mathrm{mL} \mathrm{CA} 125$ and dynamic range up to $1000 \mathrm{U} / \mathrm{mL}$ in $10 \mathrm{mM}$ phosphate buffer.

Huang deposited copper onto a Pt nanoparticle-modified electrode to create a human immunoglobulin $\mathrm{G}$ (hIgG) immunosensor via a sandwich-based assay (175). The copper layer inhibited the electrocatalytic reduction of protons to hydrogen by Pt in acidic medium. The binding of alkaline phosphatase (ALP)-antibody catalyzed the hydrolysis of ascorbic acid 2-phosphatase, producing ascorbic acid that mediated copper deposition on the electrode. A negative shift of hydrogen evolution potential was thus obtained at the $\mathrm{Pt}$ 
nanoparticle-modified electrode. A linear dependency on $\mathrm{hIgG}$ concentration was observed from $10 \mathrm{pg} / \mathrm{mL}$ to $1.0 \mu \mathrm{g} / \mathrm{mL}$ with a detection limit of $2.0 \mathrm{pg} / \mathrm{mL}$.

Lin et al. developed a nanoparticle (NP) label-based biosensor (IEB) for rapid and sensitive detection of prostate-specific antigen (PSA) in human serum (176). The captured labels were determined by highly sensitive stripping voltammetric measurement of the dissolved metallic component $(\mathrm{Cd})$ of the nanoparticles via a disposable-screen-printed electrode embedded beneath the membrane of a immunochromatographic test zone. The detection limit of the biosensor was $0.02 \mathrm{ng} / \mathrm{mL}$.

Lu and colleagues reported the fabrication of a reagentless immunosensor for rapid determination of a-l-fetoprotein (AFP) in human serum (177). The immunosensor was prepared by immobilizing alpha-1-fetoprotein antibody (AFP Ab) onto a glassy carbon electrode modified with gold nanowires and $\mathrm{ZnO}$ nanorods. A sandwich immunoassay format was employed to detect AFP with horseradish peroxidase (HRP)-labeled AFP. The resulting immunosensor enabled amperometric response for AFP from 0.5 to $160.0 \mathrm{ng} / \mathrm{mL}$ with a detection limit of $0.1 \mathrm{ng} / \mathrm{mL}$.

Qui et al. used chitosan-branched ferrocene (CS-Fc) and gold nanoparticles to design a label-free amperometric immunosensor for the sensitive detection of hepatitis B surface antigen (HBsAg) (178). The controllable electrodeposition of CS-Fc solution formed a three-dimensional film with good biocompatibility and large surface area for the assembly of Au NPs to which hepatitis B surface antibody (HBsAb) was immobilized. HBsAb concentration was determined by monitoring the amperometric response upon binding of antigen and antibody. Decreased differential pulse voltametric values were proportional to the $\mathrm{HBsAb}$ concentration in the range of $0.05-305 \mathrm{ng} / \mathrm{mL}$ with a detection limit $0.016 \mathrm{ng} /$ mL.

$\mathrm{Qu}$ et al. used functionalized silica nanoparticles (Si NPs) as protein tracer for the detection of prostate specific antigen (PSA) in human serum (179). An immunosensor was fabricated by cross-linking PSA capture antibody onto a gold electrode. After reaction with the antigen in human serum, Si NPs co-labeled with detection antibody and alkaline phosphatase (ALP) were sandwiched to form the immunocomplex. ALP carried by Si NPs converted nonelectroactive substrate into the reducing agent with the latter reducing metal ions to form electroactive metallic product at the electrode. The electrochemical immunosensor allowed for a reliable determination of PSA from 1 to $35 \mathrm{ng} / \mathrm{mL}$ with a detection limit of $0.76 \mathrm{ng}$ / $\mathrm{mL}$.

Rahman et al. doped Au nanorods (AuNRs) in a conducting polymer layer (180). The nanorod-doped polymer was used to fabricate an aptamer sensor for thrombin detection. Using a sandwich immunoassay approach, the authors reported a wide dynamic range (5 $2000 \mathrm{ng} / \mathrm{L})$ and low detection limit $(0.14 \mathrm{pM})$ for the sensor. The immunosensor was both selective and robust, indicating potential for real human serum sample analysis.

Tang and coworkers improved the sensitivity and detection limit of carcinoembryonic antigen (CEA) immunosensor using thionine (TH)-doped magnetic gold nanospheres as labels and HRP as enhancer on a anti-CEA/protein A/nanogold-modified carbon fiber microelectrode (181). TH-doped magnetic gold nanospheres (nanospheres) were labeled on HRP-bound anti-CEA as a secondary antibody (bionanospheres). A sandwich immunoassay was employed with the labeled bionanospheres using reduction of $\mathrm{H}_{2} \mathrm{O}_{2}$. The linear range of the immunosensor was 0.01 to $160 \mathrm{ng} / \mathrm{mL} \mathrm{CEA}$.

Wang et al. fabricated an amperometric human chorionic gonadotrophin (HCG) immunosensor using L-cysteine/nanosized Prussian blue bilayer films and gold 
nanoparticles (182). Current generated due to antigen-antibody binding was amplified electrocatalytically using hemoblobin and the nanosized Prussian blue bilayer films to enhance sensitivity. The linear response of the immunosensor spanned two ranges ( 0.5 to 10 $\mathrm{mIU} / \mathrm{mL}$ and 10 to $200 \mathrm{mIU} / \mathrm{mL}$ ) with a detection limit of $0.2 \mathrm{mIU} / \mathrm{mL}$.

$\mathrm{Wu}$ and coworkers reported a fast, simple, sensitive, and low-cost screen-printed reagentless immunosensor array for multianalyte detection (183). The disposable array was prepared by immobilizing horseradish peroxidase (HRP)-labeled antibody-modified gold nanoparticles in biopolymer/sol-gel-modified electrodes to obtain direct electrochemical responses of HRP. The formation of immunocomplexes decreased the sensor response due to increasing spatial blocking and impedance. This approach allowed for simultaneous measurement of carbohydrate and carcinoembryonic antigens with limit of detections approaching $\sim 0.1 \mathrm{U} /$ $\mathrm{mL}$ and $0.04 \mathrm{ng} / \mathrm{mL}$, respectively. The disposable immunosensor array and simple detection system allowed for rapid measurement of panels of tumor markers.

Yang et al. reported the fabrication of a Salmonella spp. capacitive immunosensor using an ethylene diamine/gold nanoparticle-modified glassy carbon electrode (184). Salmonella spp. monoclonal antibodies (McAbs) were first immobilized on gold nanoparticles. Interaction of the McAbs and Salmonella spp. was detected directly using electrochemical impedance spectroscopy. The relative changes in capacitance were proportional to the logarithmic values of Salmonella spp. concentrations from $1.0 \times 10^{2}$ to $1.0 \times 10^{5}$ colony forming units/ $\mathrm{mL}$ with a limit of detection of $1.0 \times 10^{2}$ colony forming units $/ \mathrm{mL}$.

\section{CONCLUSIONS}

Electrochemical sensors continue to be a mainstay of analytical chemistry as demands for increasingly selective and sensitive detection methods grows. In contrast to spectroscopy and chromatography, electrochemical sensors are inexpensive, simple, and adaptable to demanding environments where robust, miniaturized analytical methods are required. This is evident especially in the field of potentiometric sensors where recent research has focused on enhancing the ability of ion selective electrodes to operate effectively in both high concentrations of background analytes and biological milieu, where biofouling is a concern. Strategies such as analyte preconcentration and background subtraction have allowed measurements to be performed under challenging conditions (i.e., in seawater).

Incorporation of materials that resist biofouling, such as poly(ethylene glycol), has led to sensors with enhanced stability. One recent trend has been the use of fluorous liquid phases that decrease the interactions between the membrane and the ionophore due to their low polarity and polarizability, thus increasing their ability to bind target ions. Such materials are weakly solvating, reducing the effect of interfering ions. The most active area of development has been and continues to be the development and incorporation of novel ionophores into sensor membranes, with the goal of increasing sensor sensitivity, selectivity, and stability.

Of all electrochemical sensor research, sensors that exploit the unique properties of nanomaterials (i.e., nanoporous electrodes, nanoparticles, nanotubes, etc.) are the most rapidly expanding area, as evidenced by the vast quantity of recent publications related to nanomaterials. Nowhere is this more obvious than in the area of voltammetric sensors. The field of stripping voltammetry has been transformed through the use of nanomaterials with the inherent high surface area and strong adsorptive nature of such materials resulting in lowered detection limits and improved specificity. The miniaturization of electrodes has continued down to the nano regime, where measurements of fast electron kinetics are now routinely performed at diminutive analyte concentrations. Another major trend in voltammetric sensor research has been the development of sensors for the measurement of 
neurotransmitters, where improvements in both measurement techniques and electrode materials have improved the sensitivity and selectivity of such sensors.

The design and fabrication of electrochemical biosensors continues to remain a vibrant area of research. Whereas significant effort was previously directed towards glucose analysis, focus on other physiologically relevant analytes continues to drive biosensor development. Both DNA hybridization and immunological recognition was the basis of most new electrochemical detection schemes. Furthermore, the use of nanomaterials in biosensor design accounts for roughly half of all papers published in this area. Indeed, nanomaterials has enabled significant improvements in the analytical performance and utility of biosensors.

Research in the field of electrochemical sensors shows no signs of slowing down, thanks to the continued development and incorporation of nanomaterials into electrochemical sensor platforms. We believe that future work will continue to focus on improving detection limits, selectivity, and stability of electrochemical sensors. As electrochemical sensors are more frequently being used for measurements in complex biological matrices, researchers must and will continue to address the issue of fouling and stability.

\section{Acknowledgments}

The authors acknowledge the National Institutes of Health (Grant EB000708) for support of their sensor and bioanalytical research.

\section{References}

1. Bobacka J, Ivaska A, Lewenstam. A Chem Rev. 2008; 108:329-351.

2. Bakker E, Pretsch E. Trends Anal Chem. 2008; 27:612-618.

3. Lindner E, Umezawa Y. Pure Appl Chem. 2008; 80:85-104.

4. Lindner E, Gyurcsanyi REJ. Solid State Electrochem. 2009; 13:51-68.

5. Faridbod F, Ganjali MR, Dinarvand R, Norouzi P. Sensors. 2008; 8:2331-2412.

6. On JH, Cho KT, Park Y, Hahm S, Kim W, Cho JY, Hwang JH, Jun YM, Cha GS, Nam H, Kim BH. Tetrahedron. 2009; 65:1415-1423.

7. Mashhadizadeh MH, Shockravi A, Khoubi Z, Heidarian D. Electroanalysis. 2009; 21:1041-1047.

8. Bochenska M, Guzinski M, Kulesza J. Electroanalysis. 2009; 21:2054-2060.

9. Li X-G, Ma X-L, Huang M-R. Talanta. 2009; 78:498-505. [PubMed: 19203615]

10. Gupta VK, Jain AK, Al Khayat M, Bhargava SK, Raisoni JR. Electrochim Acta. 2008; 53:5409_ 5414.

11. Labib M, Hedstrom M, Amin M, Mattiasson B. Anal Chim Acta. 2009; 634:255-261. [PubMed: 19185129]

12. Arvand M, Asadollahzadeh SA. Talanta. 2008; 75:1046-1054. [PubMed: 18585182]

13. Pietrzak M, Meyerhoff ME. Anal Chem. 2009; 81:3637-3644. [PubMed: 19402723]

14. Singh K, Rahman MA, Son JI, Kim KC, Shim YB. Biosens Bioelectron. 2008; 23:1595-1601. [PubMed: 18304799]

15. Gupta VK, Goyal RN, Sharma RA. Electrochim Acta. 2009; 54:4216-4222.

16. Babu JN, Bhalla V, Kumar M, Mahajan RK, Puri RK. Tetrahedron Lett. 2008; 49:2772-2775.

17. Katsu T, Tsunamoto Y, Hanioka N, Komagoe K, Masuda K, Narimatsu S. Anal Chim Acta. 2008; 620:50-54. [PubMed: 18558123]

18. Hassouna MEM, Elsuccary SAA. Talanta. 2008; 75:1175-1183. [PubMed: 18585199]

19. Zanjanchi MA, Arvand M, Mahmoodi NO, Islamnezhad A. Electroanalysis. 2009; 21:1816-1821.

20. Zhou W, Chai Y, Yuan R, Guo J, Wu X. Anal Chim Acta. 2009; 647:210-214. [PubMed: 19591707] 
21. Javanakht M, Fard SE, Mohammadi A, Abdouss M, Ganjali MR, Norouzi P, Safaraliee L. Anal Chim Acta. 2008; 612:65-74. [PubMed: 18331859]

22. Ganjali MR, Khoshsafar H, Faridbod F, Shirzadmehr A, Javanbakht M, Norouzi P. Electroanalysis. 2009; 21:2175-2178.

23. Evtugyn GA, Stoikov II, Belyakova SV, Stoikova EE, Shamagsumova RV, Zhukov AY, Antipin IS, Budnikov HC. Talanta. 2008; 76:441-447. [PubMed: 18585303]

24. Boswell PG, Szijjarto C, Jurisch M, Gladysz JA, Rabai J, Bühlmann P. Anal Chem. 2008; 80:2084-2090. [PubMed: 18290670]

25. Lai C-Z, Koseoglu SS, Lugert EC, Boswell PG, Rabai J, Lodge TP, Buhlmann PJ. Am Chem Soc. 2009; 131:1598-1606.

26. Chumbimuni-Torres KY, Calvo-Marzal P, Wang J, Bakker E. Anal Chem. 2008; 80:6114-6118. [PubMed: 18570385]

27. Wang L, Buchanan S, Meyerhoff ME. Anal Chem. 2008; 80:9845-9847. [PubMed: 19007240]

28. Pietrzak M, Meyerhoff ME. Anal Chem. 2009; 81:5961-5965. [PubMed: 19601656]

29. Radomska A, Singhal S, Ye H, Lim M, Mantalaris A, Yue X, Drakakis EM, Toumazou C, Cass AEG. Biosens Bioelectron. 2008; 24:435-441. [PubMed: 18571918]

30. Asif MH, Fulati A, Nur O, Willander M, Brannmark C, Stralfors P, Borjesson SI, Elinder F. Appl Phys Lett. 2009; 95:23703.

31. Rzewuska A, Wojciechowski M, Bulska E, Hall EAH, Maksymiuk K, Michalska A. Anal Chem. 2008; 80:321-327. [PubMed: 18062675]

32. Gyetvai G, Nagy L, Ivaska A, Hernadi I, Nagy G. Electroanalysis. 2009; 21:1970-1976.

33. Chumbimuni-Torres KY, Thammakhet C, Galik M, Calvo-Marzal P, Wu J, Bakker E, Flechsig GU, Wang J. Anal Chem. 2009; 81:10290-10294. [PubMed: 19928777]

34. Michalska A, Pyrzynska K, Maksymiuk K. Anal Chem. 2008; 80:3921-3924. [PubMed: 18380468]

35. Veder J-P, De Marco R, Clarke G, Chester R, Nelson A, Prince K, Pretsch E, Bakker E. Anal Chem. 2008; 80:6731-6740. [PubMed: 18671410]

36. McGraw CM, Radu T, Radu A, Diamond D. Electroanalysis. 2008; 20:340-346.

37. Crespo GA, Gugsa D, Macho S, Rius FX. Anal Bioanal Chem. 2009; 395:2371-2376. [PubMed: 19760402]

38. Crespo GA, Macho S, Bobacka J, Rius FX. Anal Chem. 2009; 81:676-681. [PubMed: 19093752]

39. Parra EJ, Crespo GA, Riu J, Ruiz A, Rius FX. Analyst. 2009; 134:1905-1910. [PubMed: 19684918]

40. Crespo GA, Macho S, Rius FX. Anal Chem. 2008; 80:1316-1322. [PubMed: 18271511]

41. Guth U, Gerlach F, Decker M, Oelßner W, Vonau WJ. Solid State Electrochem. 2009; 13:27-39.

42. Kisiel A, Michalska A, Maksymiuk K, Hall EAH. Electroanalysis. 2008; 20:318-323.

43. Chen CC, Chou JC. Jpn J Appl Phys. 2009; 48:111501.

44. Švancara I, Vytřas K, Kalcher K, Walcarius A, Wang J. Electroanalysis. 2009; 21:7-28.

45. Zima J, Švancara I, Barek J, Vytřas K. Crit Rev Anal Chem. 2009; 39:204-227.

46. Yosypchuk B, Barek J. Crit Rev Anal Chem. 2009; 39:189-203.

47. Stetter JR, Li J. Chem Rev. 2008; 108:352-366. [PubMed: 18201108]

48. Yogeswaran U, Chen SM. Sensors. 2008; 8:290-313.

49. Mays DE, Hussam A. Anal Chim Acta. 2009; 646:6-16. [PubMed: 19523550]

50. Bobrowski A, Królicka A, Zarębski J. Electroanalysis. 2009; 12:1449-1458.

51. Amatore C, Oleinick A, Svir I. Anal Chem. 2008; 80:7947-7956. [PubMed: 18826243]

52. Amatore C, Oleinick AI, Svir I. Anal Chem. 2009; 81:4397-4405. [PubMed: 19402648]

53. Guo JD, Lindner E. Anal Chem. 2009; 81:130-138. [PubMed: 19117449]

54. Douglass EF, Driscoll PF, Liu DL, Burnham NA, Lambert CR, McGimpsey WG. Anal Chem. 2008; 80:7670-7677. [PubMed: 18811215]

55. Menshykau D, Compton RG. Electroanalysis. 2008; 20:2387-2394. 
56. Bae JH, Lim YR, Jung W, Silbey RJ, Sung J. Anal Chem. 2009; 81:578-583. [PubMed: 19090762]

57. Lee CY, Bond AM. Anal Chem. 2009; 81:584-594. [PubMed: 19140776]

58. Sheth DB, Diefes R, Gratzl M. Anal Chem. 2009; 81:2129-2134. [PubMed: 19216554]

59. Ogurtsov VI, Beni V, Strutwolf J, Arrigan DWM. Electroanalysis. 2009; 21:68-76.

60. Zhou M, Guo JD, Guo LP, Bai J. Anal Chem. 2008; 80:4642-4650. [PubMed: 18476717]

61. Trammell SA, Zeinali M, Melde BJ, Charles PT, Velez FL, Dinderman MA, Kusterbeck A, Markowitz MA. Anal Chem. 2008; 80:4627-4633. [PubMed: 18470994]

62. Park JY, Chang BY, Nam H, Park SM. Anal Chem. 2008; 80:8035-8044. [PubMed: 18826248]

63. Safavi A, Maleki N, Farjami E, Mahyari FA. Anal Chem. 2009; 81:7538-7543. [PubMed: 19681595]

64. Batista IV, Lanz MRV, Dias ILT, Tanaka S, Tanaka AA, Sotomayor M. Analyst. 2008; 133:16921699. [PubMed: 19082071]

65. Gholivand MB, Amiri M. Electroanalysis. 2009; 21:2461-2467.

66. Prasad KS, Arun AB, Rekha PD, Young CC, Chang JL, Zen JM. Electroanalysis. 2009; 21:16461650.

67. Popp A, Yilmazoglu O, Kaldirim O, Schneider JJ, Pavlidis D. Chem Commun. 2009:3205-3207.

68. Dumitrescu I, Unwin PR, Wilson NR, Macpherson JV. Anal Chem. 2008; 80:3598-3605. [PubMed: 18410133]

69. Khan MAK, Keirman K, Petryk M, Kraatz HB. Anal Chem. 2008; 80:2574-2582. [PubMed: 18298097]

70. Kachoosangi RT, Wildgoose GG, Compton RG. Electroanalysis. 2008; 20:2495-2500.

71. Rahman MA, Won MS, Kwon HH, Yoon JH, Park DS, Shim YB. Anal Chem. 2008; 80:53075311. [PubMed: 18553943]

72. Wei M, Terashima C, Lv M, Fujishima A, Gu ZZ. Chem Commun. 2009:3624-3626.

73. Hutton L, Newton ME, Unwin PR, Macpherson JV. Anal Chem. 2009; 81:1023-1032. [PubMed: 19117391]

74. Karam P, Halaoui LI. Anal Chem. 2008; 80:5441-5448. [PubMed: 18543955]

75. Crowley K, O’Malley E, Morrin A, Smyth MR, Killard AJ. Analyst. 2008; 133:391-399. [PubMed: 18299755]

76. Wen M, Liu HQ, Zhang F, Zhu YZ, Liu D, Tian Y, Wu QS. Chem Commun. 2009:4530-4532.

77. Mann TS, O’Hagan L, Ertl P, Sparkes DI, Mikkelsen SR. Anal Chem. 2008; 80:2988-2992. [PubMed: 18341302]

78. Zachek MK, Takmakov P, Moody B, Wightman RM, McCarty GS. Anal Chem. 2009; 81:62586265. [PubMed: 19552423]

79. Li YX, Bergman D, Zhang B. Anal Chem. 2009; 81:5496-5502. [PubMed: 19514727]

80. Yang CX, Sun P. Anal Chem. 2009; 81:7496-7500. [PubMed: 19639955]

81. Hu JP, Holt KB, Foord JS. Anal Chem. 2009; 81:5663-5670. [PubMed: 19545137]

82. Strand AM, Venton BJ. Anal Chem. 2008; 80:3708-3715. [PubMed: 18416534]

83. Pai RS, Walsh KM, Crain MM, Roussel TJ, Jackson DJ, Baldwin RP, Keynton RS, Naber JF. Anal Chem. 2009; 81:4762-4769. [PubMed: 19459620]

84. Jena BK, Raj CR. Anal Chem. 2008; 80:4836-4844. [PubMed: 18444693]

85. Janegitz BC, Marcolino LH, Campana SP, Faria RC, Fatibello O. Sens Actuators, B. 2009; 142:260-266.

86. Morton J, Havens N, Mugweru A, Wanekaya AK. Electroanalysis. 2009; 21:1597-1603.

87. Xu H, Zeng LP, Xing SJ, Xian YZ, Shi GY. Electroanalysis. 2008; 20:2655-2662.

88. Toghill KE, Xiao L, Wildgoose GG, Compton RG. Electroanalysis. 2009; 21:1113-1118.

89. Yantasee W, Hongsirikarn K, Warner CL, Choi D, Sangvanich T, Toloczko MB, Warner MG,

Fryxell GE, Addleman RS, Timchalk C. Analyst. 2008; 133:348-355. [PubMed: 18299749]

90. Rico MAG, Olivares-Marín M, Gil EP. Talanta. 2009; 80:631-635. [PubMed: 19836530] 
91. Tesarova E, Baldrianova L, Hocevar SB, Svancara I, Vytras K, Ogorevc B. Electrochim Acta. 2009; 54:1506-1510.

92. Zou LN, Zhang YF, Qin HL, Ye BX. Electroanalysis. 2009; 21:2563-2568.

93. Delgado L, Carrero H, Fernandez L. Electroanalysis. 2009; 21:2713-2717.

94. Kim Y, Amemiya S. Anal Chem. 2008; 80:6056-6065. [PubMed: 18613700]

95. Hermans A, Keithley RB, Kita JM, Sombers LA, Wightman RM. Anal Chem. 2008; 80:40404048. [PubMed: 18433146]

96. Shang FJ, Zhou L, Mahmoud KA, Hrapovic S, Liu YL, Moynihan HA, Glennon JD, Luong JHT. Anal Chem. 2009; 81:4089-4098. [PubMed: 19382752]

97. Deng CY, Chen JH, Wang MD, Xiao CH, Nie Z, Yao SZ. Biosens Bioelectron. 2009; 24:20912094. [PubMed: 19084392]

98. Özcan A, Şahin Y. Electroanalysis. 2009; 21:2363-2370.

99. Yan J, Zhou YC, Yu P, Su L, Mao LQ, Zhang DQ, Zhu DB. Chem Commun. 2008:4330-4332.

100. Schreiber F, Polerecky L, de Beer D. Anal Chem. 2008; 80:1152-1158. [PubMed: 18197634]

101. Shim JH, Lee Y. Anal Chem. 2009; 81:8571-8576. [PubMed: 19775121]

102. Shin JH, Privett BJ, Kita JM, Wightman RM, Schoenfisch MH. Anal Chem. 2008; 80:68506859. [PubMed: 18714964]

103. Ai F, Chen H, Zhang SH, Liu SY, Wei F, Dong XY, Cheng JK, Huang WH. Anal Chem. 2009; 81:8453-8458. [PubMed: 19778000]

104. Hashemi P, Dankoski EC, Petrovic J, Keithley RB, Wightman RM. Anal Chem. 2009; 81:94629471. [PubMed: 19827792]

105. Hason S, Stepankova S, Kourilova A, Vetterl V, Lata J, Fojta M, Jelen F. Anal Chem. 2009; 81:4302-4307. [PubMed: 19402672]

106. Wang ZH, Zhu HF, Zhang H, Gao GQ, Sun ZD, Liu HP, Zhao XL. Electrochim Acta. 2009; 54:7531-7535.

107. Wang J. Chem Rev. 2008; 108:814-825. [PubMed: 18154363]

108. Lad U, Khokhar S, Kale GM. Anal Chem. 2008; 80:7910-7917. [PubMed: 18975861]

109. Song SP, Wang LH, Li J, Zhao JL, Fan CH. Trends Anal Chem. 2008; 27:108-117.

110. Hianik T, Wang J. Electroanalysis. 2009; 21:1223-1235.

111. Agui L, Yanez-Sedeno P, Pingarron JM. Anal Chim Acta. 2008; 622:11-47. [PubMed: 18602533]

112. Pingarron JM, Yanez-Sedeno P, Gonzalez-Cortes A. Electrochim Acta. 2008; 53:5848-5866.

113. Sanvicens N, Pastells C, Pascual N, Marco MP. Trends Anal Chem. 2009; 28:1243-1252.

114. Jiang XS, Li DY, Xu X, Ying YB, Li YB, Ye ZZ, Wang JP. Biosens Bioelectron. 2008; 23:15771587. [PubMed: 18358712]

115. Palchetti I, Mascini M. Anal Bioanal Chem. 2008; 391:455-471. [PubMed: 18283441]

116. Walcarius A, Collinson MM. Annu Rev Anal Chem. 2009; 2:121-143.

117. Vamvakaki V, Hatzimarinaki M, Chaniotakis N. Anal Chem. 2008; 80:5970-5975. [PubMed: 18593196]

118. Lopez BP, Merkoci A. Analyst. 2009; 134:60-64. [PubMed: 19082175]

119. Fu YC, Chen C, Xie QJ, Xu XH, Zou C, Zhou QM, Tan L, Tang H, Zhang YY, Yao SZ. Anal Chem. 2008; 80:5829-5838. [PubMed: 18593192]

120. Rowinski P, Rowinska M, Heller A. Anal Chem. 2008; 80:1746-1755. [PubMed: 18247485]

121. Gopalan AI, Lee KP, Ragupathy D, Lee SH, Lee JW. Biomaterials. 2009; 30:5999-6005. [PubMed: 19674780]

122. Barbadillo M, Casero E, Petit-Dominguez MD, Vazquez L, Pariente F, Lorenzo E. Talanta. 2009; 80:797-802. [PubMed: 19836554]

123. Ciobanu M, Taylor DE, Wilburn JP, Cliffel DE. Anal Chem. 2008; 80:2717-2727. [PubMed: 18345647]

124. Masson JF, Kranz C, Mizaikoff B, Gauda EB. Anal Chem. 2008; 80:3991-3998. [PubMed: 18457410] 
125. Peng Y, Jiang DL, Su L, Zhang L, Yan M, Du JJ, Lu YF, Liu YN, Zhou FM. Anal Chem. 2009; 81:9985-9992. [PubMed: 19928778]

126. El Ichi S, Marzouki MN, Korri-Youssoufi H. Biosens Bioelectron. 2009; 24:3084-3090. [PubMed: 19423328]

127. Deng ZF, Rui Q, Yin X, Liu HQ, Tian Y. Anal Chem. 2008; 80:5839-5846. [PubMed: 18593195]

128. Wegerich F, Turano P, Allegrozzi M, Mohwald H, Lisdat F. Anal Chem. 2009; 81:2976-2984. [PubMed: 19296689]

129. Jamal M, Worsfold O, McCormac T, Dempsey E. Biosens Bioelectron. 2009; 24:2926-2930. [PubMed: 19356918]

130. Lin ZY, Sun JJ, Chen JH, Guo L, Chen YT, Chen GN. Anal Chem. 2008; 80:2826-2831. [PubMed: 18315011]

131. So M, Hvastkovs EG, Bajrami B, Schenkman JB, Rusling JF. Anal Chem. 2008; 80:1192-1200. [PubMed: 18189370]

132. Lubin AA, Hunt BVS, White RJ, Plaxco KW. Anal Chem. 2009; 81:2150-2158. [PubMed: 19215066]

133. Wu YF, Liu SQ, He L. Anal Chem. 2009; 81:7015-7021. [PubMed: 19583218]

134. Ozkan-Ariksoysal D, Tezcanli B, Kosova B, Ozsoz M. Anal Chem. 2008; 80:588-596. [PubMed: 18181582]

135. Zhang XZ, Jiao K, Liu SF, Hu YW. Anal Chem. 2009; 81:6006-6012. [PubMed: 20337392]

136. Zhang YL, Wang Y, Wang HB, Jiang JH, Shen GL, Yu RQ, Li JH. Anal Chem. 2009; 81:19821987. [PubMed: 19173619]

137. Chen JH, Zhang J, Huang LY, Lin XH, Chen GN. Biosens Bioelectron. 2008; 24:349-355. [PubMed: 18502637]

138. Chen JH, Zhang J, Wang K, Lin XH, Huang LY, Chen GN. Anal Chem. 2008; 80:8028-8034. [PubMed: 18816068]

139. Xiao Y, Lou XH, Uzawa T, Plakos KJI, Plaxco KW, Soh HTJ. Am Chem Soc. 2009; 131:1531115316.

140. Hu KC, Lan DX, Li XM, Zhang SS. Anal Chem. 2008; 80:9124-9130. [PubMed: 19551936]

141. Swensen JS, Xiao Y, Ferguson BS, Lubin AA, Lai RY, Heeger AJ, Plaxco KW, Soh HT. J Am Chem Soc. 2009; 131:4262-4266. [PubMed: 19271708]

142. Deng CY, Chen JH, Nie LH, Nie Z, Yao SZ. Anal Chem. 2009; 81:9972-9978. [PubMed: 20000640]

143. Zhang SS, Xia JP, Li XM. Anal Chem. 2008; 80:8382-8388. [PubMed: 18939854]

144. Cash KJ, Ricci F, Plaxco KW. J Am Chem Soc. 2009; 131:6955. [PubMed: 19413316]

145. Sun W, Wang Y, Li XQ, Wu J, Zhan TR, Jiao K. Electroanalysis. 2009; 21:2454-2460.

146. Du Y, Li BL, Wei H, Wang YL, Wang EK. Anal Chem. 2008; 80:5110-5117. [PubMed: 18522435]

147. Ricci F, Bonham AJ, Mason AC, Reich NO, Plaxco KW. Anal Chem. 2009; 81:1608-1614. [PubMed: 19199570]

148. Ghanbari K, Bathaie SZ, Mousavi MF. Biosens Bioelectron. 2008; 23:1825-1831. [PubMed: 18406598]

149. Abu-Rabeah K, Ashkenazi A, Atias D, Amir L, Marks RS. Biosens Bioelectron. 2009; 24:34613466. [PubMed: 19501501]

150. Escamilla-Gomez V, Campuzano S, Pedrero M, Pingarron JM. Talanta. 2008; 77:876-881.

151. Mantzila AG, Maipa V, Prodromidis MI. Anal Chem. 2008; 80:1169-1175. [PubMed: 18217725]

152. Pournaras AV, Koraki T, Prodromidis MI. Anal Chim Acta. 2008; 624:301-307. [PubMed: 18706337]

153. Salam F, Tothill IE. Biosens Bioelectron. 2009; 24:2630-2636. [PubMed: 19233634]

154. Mwilu SK, Aluoch AO, Miller S, Wong P, Sadik OA. Anal Chem. 2009; 81:7561-7570. [PubMed: 19689112]

155. Nguyen BTT, Koh G, Lim HS, Chua AJS, Ng MML, Toh CS. Anal Chem. 2009; 81:7226-7234. [PubMed: 19663392] 
156. Wang RH, Wang Y, Lassiter K, Li YB, Hargis B, Tung S, Berghman L, Bottje W. Talanta. 2009; 79:159-164. [PubMed: 19559858]

157. Barton AC, Davis F, Higson SP. J Anal Chem. 2008; 80:6198-6205.

158. Kurtinaitiene B, Ambrozaite D, Laurinavicius V, Ramanaviciene A, Ramanavicius A. Biosens Bioelectron. 2008; 23:1547-1554. [PubMed: 18294837]

159. Zhang XT, Wu YF, Tu YF, Liu SQ. Analyst. 2008; 133:485-492. [PubMed: 18365118]

160. Liu XP, Deng YJ, Jin XY, Chen LG, Jiang JH, Shen GL, Yu RQ. Anal Biochem. 2009; 389:6368. [PubMed: 19303858]

161. March C, Manclus JJ, Jimenez Y, Arnau A, Montoya A. Talanta. 2009; 78:827-833. [PubMed: 19269436]

162. Ramon-Azcon J, Valera E, Rodriguez A, Barranco A, Alfaro B, Sanchez-Baeza F, Marco MP. Biosens Bioelectron. 2008; 23:1367-1373. [PubMed: 18234487]

163. Nassef HM, Civit L, Fragoso A, O’Sullivan CK. Anal Chem. 2009; 81:5299-5307. [PubMed: 19469538]

164. Nassef HM, Redondo MCB, Ciclitira PJ, Ellis HJ, Fragoso A, O'Sullivan CK. Anal Chem. 2008; 80:9265-9271. [PubMed: 19551990]

165. Pividori MI, Lermo A, Bonanni A, Alegret S, del Valle M. Anal Biochem. 2009; 388:229-234. [PubMed: 19250919]

166. Giroud F, Gorgy K, Gondran C, Cosnier S, Pinacho DG, Marco MP, Sanchez-Baeza FJ. Anal Chem. 2009; 81:8405-8409. [PubMed: 19824714]

167. Koh WCA, Choe ES, Lee DK, Chang SC, Shim YB. Biosens Bioelectron. 2009; 25:211-217. [PubMed: 19632105]

168. Kwon SJ, Yang H, Jo K, Kwak J. Analyst. 2008; 133:1599-1604. [PubMed: 18936839]

169. Prabhulkar S, Alwarappan S, Liu GD, Li CZ. Biosens Bioelectron. 2009; 24:3524-3530. [PubMed: 19520564]

170. Preechaworapun A, Ivandini TA, Suzuki A, Fujishima A, Chailapakul O, Einaga Y. Anal Chem. 2008; 80:2077-2083. [PubMed: 18271566]

171. Qu L, Xia SH, Bian C, Sun JZ, Han JH. Biosens Bioelectron. 2009; 24:3419-3424. [PubMed: 19110412]

172. Barton AC, Davis F, Higson SP. J Anal Chem. 2008; 80:9411-9416.

173. Chen XJ, Wang YY, Zhou JJ, Yan W, Li XH, Zhu J. J Anal Chem. 2008; 80:2133-2140.

174. Bangar MA, Shirale DJ, Chen W, Myung NV, Mulchandani A. Anal Chem. 2009; 81:2168-2175. [PubMed: 19281260]

175. Huang Y, Wen Q, Jiang JH, Shen GL, Yu RQ. Biosens Bioelectron. 2008; 24:600-605. [PubMed: 18640025]

176. Lin YY, Wang J, Liu GD, Wu H, Wai CM, Lin YH. Biosens Bioelectron. 2008; 23:1659-1665. [PubMed: 18406127]

177. Lu XX, Bai HP, He P, Cha YY, Yang GM, Tan L, Yang YH. Anal Chim Acta. 2008; 615:158164. [PubMed: 18442521]

178. Qiu JD, Liang RP, Wang R, Fan LX, Chen YW, Xia XH. Biosens Bioelectron. 2009; 25:852857. [PubMed: 19767192]

179. Qu B, Chu X, Shen G, Yu RQ. Talanta. 2008; 76:785-790. [PubMed: 18656659]

180. Rahman MA, Son JI, Won MS, Shim YB. Anal Chem. 2009; 81:6604-6611. [PubMed: 20337374]

181. Tang DP, Yuan R, Chal YQ. Anal Chem. 2008; 80:1582-1588. [PubMed: 18220412]

182. Wang JF, Yuan R, Chai YQ, Yin B, Xu Y, Guan S. Electroanalysis. 2009; 21:707-714.

183. Wu J, Yan YT, Yan F, Ju HX. Anal Chem. 2008; 80:6072-6077. [PubMed: 18593191]

184. Yang GJ, Huang JL, Meng WJ, Shen M, Jiao XA. Anal Chim Acta. 2009; 647:159-166. [PubMed: 19591700] 


\section{Biographies}

Benjamin J. Privett is a graduate student in the laboratory of Dr. Mark Schoenfisch at the University of North Carolina at Chapel Hill. He earned a B.S in Chemistry from Centre College in 2005. Prior to graduate school, he was an NSF REU participant at the University of Idaho. His Ph.D. research involves the development of sol-gel-derived sensors.

Jae Ho Shin is an Assistant Professor in the Department of Chemistry at Kwangwoon University in Seoul, South Korea. He earned his Ph.D. in Chemistry from the University of North Carolina at Chapel Hill in 2006 working under the direction of Dr. Mark Schoenfisch. His research interests include chemical sensors and nanotechnology.

Mark H. Schoenfisch is Professor of Chemistry at the University of North Carolina at Chapel Hill. His group's research interests span in vivo chemical sensors, protein adhesion related to biocompatibility, bacteria biofilms, and nano-therapeutics. 